\title{
Residential Location, Travel, and Energy Use in the Hangzhou Metropolitan Area
}

\author{
Petter Næss \\ Aalborg University ${ }^{a}$
}

\begin{abstract}
This paper presents the results of a study examining the influence of residential location on travel behavior in the Hangzhou Metropolitan Area, China. The location of the dwelling relative to the center hierarchy of the metropolitan area is found to exert a considerable influence on the travel behavior of the respondents. On average, living close to the center of Hangzhou contributes to less overall travel, a higher proportion of trips by bicycle and on foot, and lower consumption of energy for transport. The location of the dwelling relative to the closest second-order and third-order center also influences travel, but not to the same extent as proximity to the city center. These geographical differences in travel behavior are independent of residential preferences and of attitudes toward transport and environmental issues, and therefore cannot be explained by residential self-selection.
\end{abstract}

\section{Introduction}

Previous studies in a number of European, American, and Australian cities have shown that residents living close to the city center travel less than their outer-area counterparts and carry out a higher proportion of their travel by bicycle or on foot (e.g. Fouchier 1998; Mogridge 1985; Newman and Kenworthy 1989, 1999; Næss 2006b; Næss and Jensen 2004; Næss et al. 1995; Schwanen et al. 2001; Stead and Marshall 2001; Zegras 2010). These relationships between residential location and travel behavior make up an important part of the foundation for the policies of planning authorities in several European countries aiming to promote compact and concentrated urban development. However, very few studies of land use and travel have been carried out in an Asian context. Moreover, many earlier studies of this issue have been criticized for failing to control for other possible sources of influence and for not being able to establish whether a causal relationship exists between urban structure and travel behavior.

This paper is based on a comprehensive study of residential location and travel in an affluent Chinese urban region: the Hangzhou Metropolitan Area (Næss 2007). The focus of the study is the transport consequences of the location of the residence within the spatial/functional urban structure. ${ }^{1}$ Hangzhou is the capital as well as the economic and political center of Zhejiang

\footnotetext{
${ }^{a}$ petter@plan.aau.dk

${ }^{1}$ In this context, the spatial/functional urban structure applies to the geographical distribution and fabric of the building stock, the relative location of different functions (residences, workplaces, public institutions, and services) 
Province and is located in south-eastern China, 180 kilometers south-west of Shanghai. The Hangzhou Metropolitan Area has four million inhabitants, of which two million live in the continuously built-up urban area of the city of Hangzhou.

In which parts of Hangzhou Metropolitan Area will it be favorable to locate future residential development if the aim is to limit or reduce the amount of private motoring? Needless to say, such knowledge is highly relevant to policy-making and planning, especially in the context of global warming and dwindling oil resources. Nearly one-half of the world's current construction of buildings takes place in China, especially in the growing metropolitan areas along the eastern coast. In Hangzhou, the pace of change is rapid; housing areas constructed twenty years ago are considered old. Compared to cities in Europe and America, where it usually takes several decades to bring about a significant change in urban form, the much higher pace of construction in Chinese cities implies that the increase in building stock during the coming decades may change the spatial structures of these cities dramatically. If Chinese cities follow the path of urban development and transport policy that North American and many European cities followed during the second half of the twentieth century, a strong increase in urban motoring must be expected, with associated problems related to oil consumption, air pollution, health, traffic accidents, and reduced accessibility to facilities for people who do not possess a private car. It is therefore important, from a policy perspective, to identify urban development strategies that have the potential to reduce automobile dependency and provide a high level of access to workplaces, service facilities and other urban functions without necessitating a high level of individual motor vehicle use.

Like their European counterparts, most Chinese cities have historical urban cores containing the highest concentration of workplaces, retail stores, and other service facilities. Typically, Chinese cities have a hierarchical center structure with a main center, a few sub-centers, several community centers and a number of local centers (Cheng 2004). The Hangzhou Metropolitan area is no exception; the inner city has an unchallenged status as the dominating center of the metropolitan area. Population density is considerably higher in the inner city than in the outer parts of the region. There is a clear tendency to decreasing density of population as well as workplaces when the distance from the city center increases. Offices and service-sector workplaces are particularly concentrated in downtown Hangzhou and the areas immediately surrounding it. Industrial workplaces are to a higher extent located in a belt in the outer eastern and northern parts of the city and in the new Economic and Technical Development zones of Binjiang (on the south side of the Qiangtang river) and Xiasha.

The Hangzhou Metropolitan Area also includes a number of lower-order centers. The central parts of the towns of Xiaoshan and Yuhang (northeast) could be classified as second-order centers. Both these towns possess a comprehensive set of center functions, with a variety of workplaces as well as service facilities. The range and number of specialized functions is, however, lower than in the central part of Hangzhou. Six smaller towns and villages outside the city of Hangzhou-Yuhang (west), Liangzhu, Tangxi, Yipeng, Guali, and Linpu—can be classified as third-order centers. These centers, too, include a fairly comprehensive set of center functions, but with a considerably more narrow range (generally limited to less-specialized functions) and with a lower number of facilities within each category than the higher-order centers.

within the urban area, the transport system (road network, public transport provision, and parking conditions), and the urban "green" and "blue" structures (more or less natural areas within and close to the city, and lakes, rivers and creeks). 


\section{Theoretical Background And Research Questions}

A comprehensive account of the theoretical basis of the present study is given in Næss (2007, 31-58) (see also Næss 2004, 2005, 2006b). Only a few main points will be reiterated here. According to theories of transport geography and transport economy, the travel between different destinations is assumed to be influenced on the one hand by the reasons people may have for going to a place, and on the other hand by the discomfort involved when traveling to this location (Jones 1978). By determining the distances between locations where different activities may take place, and by facilitating various modes of traveling, the urban structure makes up a set of conditions that encourage some types of travel behavior and discourage others. The causes of travel behavior also include travelers' personal characteristics, such as age, sex, income, and professional status, as well as their values, norms, lifestyles, and acquaintances. The emerging transportation pattern (choices of destinations, modes of traveling, and trip routes) is a result of people's resources, needs, and wishes, as modified by the constraints and opportunities given by the structural conditions of society.

In spite of decentralizing trends, most cities - in China as well as in Western countries_-still have a higher concentration of workplaces, retail, public agencies, cultural events, and leisure facilities in the historical urban center and its immediate surroundings than in the peripheral parts of the urban area (see, e.g., Newman and Kenworthy 1999, 94-95, Cheng 2004). The inner and central parts of the metropolitan area include the largest supply of work opportunities, the broadest range of commodities in the shops, and the greatest diversity of service facilities. For residents of the inner and central parts of the city, the distances to this concentration of facilities will be short. Inner-city residents could thus be expected, on average, to make shorter daily trips than their outer-area counterparts, with a higher proportion of destinations within acceptable walking or bicycling distance.

Figure 1 shows a simplified model of the ways in which individual characteristics, urban structural elements, and social conditions are assumed to influence daily traveling distances through accessibility ${ }^{2}$ of facilities, rationales for activity participation and location of activities, frequencies of activity participation, and actual location of activities ${ }^{3}$. The location of the residence relative to various centers and facilities, combined with the transport infrastructure on the relevant stretches, determines how accessible these centers and facilities are from the dwelling. Accessibility will be inversely proportional to the friction of distance (Lloyd and Dicken 1977), defined as a function of the time consumption, economic expenses and inconvenience involved when traveling from one place to another. Other things equal, accessibility will of course be highest for the closest facilities. However, ease of access varies with travel mode, depending on (among other factors) the layout of the public transport network, driving con-

\footnotetext{
${ }^{2}$ Here, accessibility refers to the ease with which a given location can be reached, depending on its proximity, the transport infrastructure connecting to it, and visitors' individual mobility resources.

${ }^{3}$ The figure does not show conditions influencing the travel modes used, which make up another important aspect of the study. Travel modes could be expected to be influenced indirectly by the factors shown in Figure 2 through their influence on traveling distances, and directly by individual resources and motives, transport infrastructure and social environments.
} 
ditions along the road network, conditions for walking and bicycling, and individual mobility capabilities.

Residents' individual resources, motivations, and social environments influence their rationales for activity participation (including the balance between motivation to participate in activities and the friction of distance) and activity location (notably the balance between proximity and quality of facilities). Combined with the accessibility of various facilities, these rationales influence the frequency of activity participation as well as the actual locations chosen for the various activities. The total distance traveled is a product of the geographical locations chosen for the activities in which the resident participates, the distance along the transport infrastructure network from the residence to these locations, and the frequencies at which the various activities are carried out. ${ }^{4}$

There are also mutual influences between the urban structural situation of the dwelling (location relative to various centers and facilities and to local transport infrastructure) and the characteristics of individuals and households. The possibility that respondents with a priori socioeconomic characteristics and attitudes predisposing them to certain types of travel behavior (e.g. a preference for local facilities and travel by bicycle) will be overrepresented in certain locations necessitates multivariate control for such characteristics when assessing the influence of urban structural variables. On the other hand, certain socioeconomic characteristics and attitudes (e.g. car ownership and transport attitudes) may themselves be influenced by the urban structural situation of the dwelling.

With these theoretical considerations as a background, the study of the Hangzhou Metropoli$\tan$ Area has addressed the following research questions, of which the first is the one focused on in this article:

1. Which relationships exist between the location of the residence within the urban structure and travel behavior (amount of transport and modal split), when taking into consideration demographic, socioeconomic as well as attitudinal factors?

2. Does the location of the residence within the urban structure influence the range and frequency of activities in which people engage?

3. On which rationales do people base their choices of activity locations and travel modes?

4. Are the relationships between residential location and travel behavior different among different subgroups of the population?

\section{Methods}

This study used a combination of quantitative and qualitative research methods; urban structural conditions were determined by means of maps, aerial photographs, and visits to the areas

\footnotetext{
${ }^{4}$ This presupposes that the residents choose more or less the shortest routes. Our qualitative material clearly indicates that this is the case for daily-life travel (Næss 2007, 144-149; see also Næss 2005, 213-214).
} 


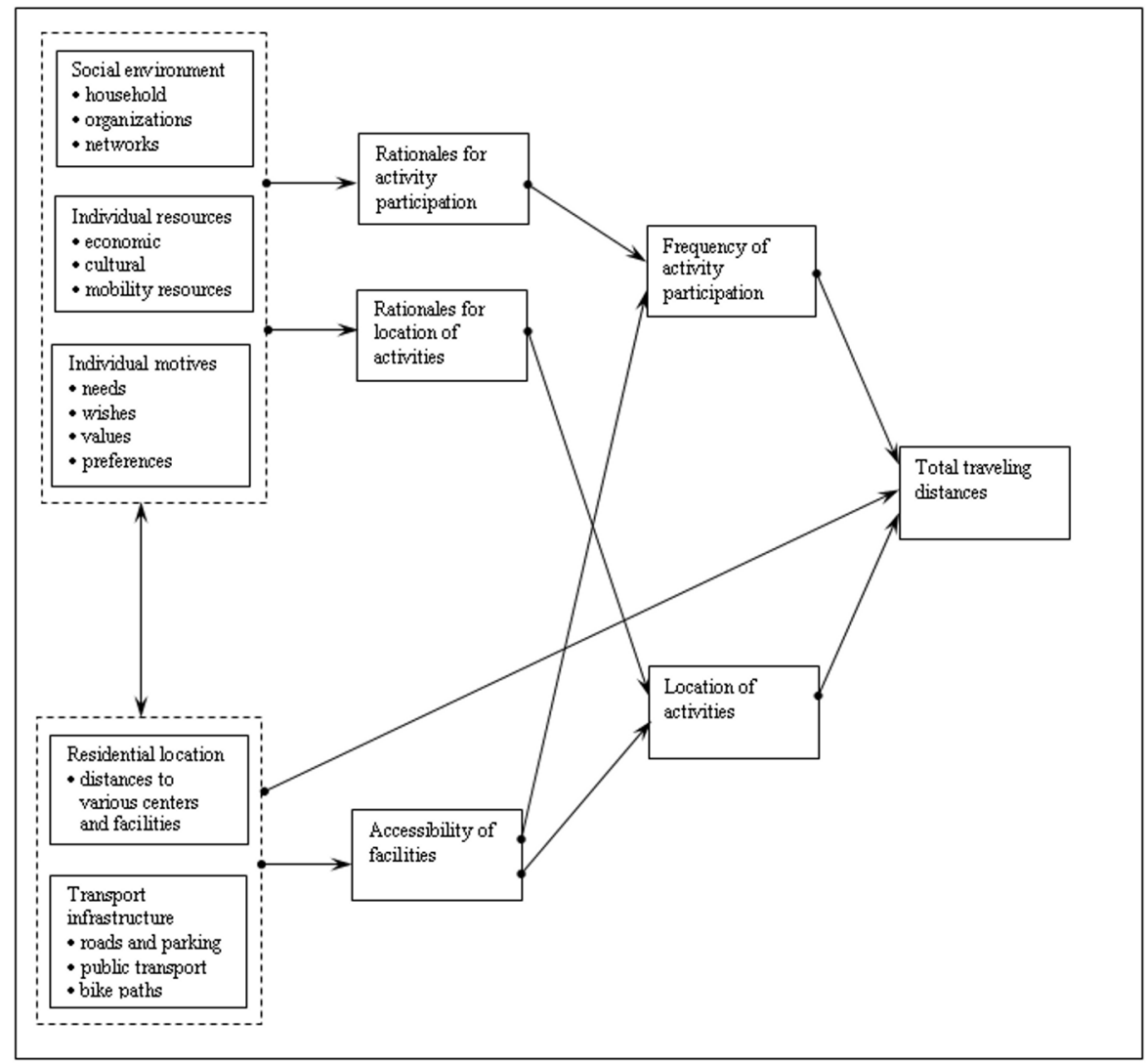

Figure 1: Model showing the assumed links between urban structural, individual and social conditions, accessibility to facilities, rationales for activity participation and location of activities, actual activity participation and location of activities, and total traveling distances

investigated; 28 qualitative interviews were conducted; and a survey questionnaire was completed by 3154 individuals in June 2005. This paper concentrates on the quantitative component of the study. Survey respondents were recruited from residential areas varying in their urban structural situation in terms of distance to downtown Hangzhou and to local centers, density, availability of local facilities etc. Questionnaires were distributed personally to residents of the selected residential areas willing to participate in the investigation. ${ }^{5}$ Ninety-two

\footnotetext{
${ }^{5}$ In each area, respondents were recruited by ringing doorbells, starting from a randomly chosen building within the demarcated area. Investigation assistants (masters and doctoral students from Zhejiang University) explained the purpose of the study and the content of the questionnaire, requesting one of the household members (the person above 15 years next to have her/his birthday) to answer the questions. Thus, all respondents were single individuals, and there was only one respondent from each household. The investigation assistants also collected the completed questionnaires. This procedure went on until the number of collected questionnaires in each area was considered sufficiently high or no more willing participants could be found. At the outset, we intended to recruit 100 respondents from each of 30 residential areas selected according to the criteria mentioned above. However, in some of the selected areas, fewer than 100 persons could be recruited. Additional respondents were therefore selected from a number of other locations. After having received the questionnaires, a quality inspection of the received material was conducted and invalid questionnaires were eliminated. To compensate for eliminated responses, additional respondents were recruited. These latter respondents were selected among acquaintances of the investigation team.
} 
percent of the respondents were recruited from the 40 residential areas shown in Figure 2. In addition, 242 respondents were recruited from 75 other locations within the metropolitan area, each contributing fewer than 10 respondents. The city center of Hangzhou is located at the northeastern shore of the lake, close to residential area 28.

The decision to recruit participants from a limited number of demarcated residential areas (instead of, for example, drawing a random sample from all inhabitants of the Hangzhou Metropolitan Area) was partly motivated by a desire to map several urban structural properties in each area and include this range of characteristics as variables in our study. Limiting the number of locations was also necessary in order to avoid making the process of delivering and collecting questionnaires too laborious. Because questionnaires were only delivered to those residents of the chosen areas who were at home and who agreed to participate in the investigation, it is not possible to calculate a response rate based on the numbers of distributed and collected questionnaires. However, based on information from the research assistants, a high proportion of visits resulted in participation by the residents in the main survey. The method of selecting respondents also makes it problematic to carry out statistical generalizations from our sample of respondents to the populations of the Hangzhou Metropolitan Area. Therefore, levels of statistical significance are only indicators of the certainty of the various relationships found within the sample. A generalization from our sample to the inhabitants of the metropolitan area must instead rely on qualitative arguments to a large extent (Sayer 1992, 103): To what extent do the residential areas in this study, seen as a whole, deviate from the residential areas of the Hangzhou Metropolitan Area in general with respect to characteristics relevant to our research questions? To what extent do relevant characteristics of the individual respondents, also seen as a whole, differ from the characteristics of the total population of the Hangzhou Metropolitan Area? Does it appear likely and reasonable to assume that differences between the sample and the population of Hangzhou Metropolitan Area have exerted decisive influence on the relationships found between residential location and travel behavior? (For a more thorough discussion, Næss see 2004, 153-156.)

Table 1 shows some key characteristics of the respondents of the main survey. Female respondents are somewhat overrepresented, whereas the proportion of students appears to be quite low (statistics for the proportion of students among the metropolitan population are not available). Moreover, the proportion of respondents belonging to a household with at least one car is only one-third of what it was among the metropolitan population two years later in 2007. Given the very rapid increase in the rate of car ownership in Hangzhou (the proportion of households owning a car increased tenfold from 2002 to 2007), the proportion of respondents belonging to a car-owning household in 2005 was probably not dramatically lower than the proportion of the metropolitan population. Apart from this, the respondents appear to be fairly representative of the metropolitan population as a whole and of their residential areas. In addition, multivariate statistical control makes it possible to neutralize any known biases between the sample and the population of the metropolitan area. If, for example, gender is included among the independent variables in the multivariate analysis, the controlled relationship between residential location and travel will not be seriously biased by any distortion in the gender distribution of the sample. 
Table 1: Demographic and socioeconomic characteristics of survey respondents and the general population of Hangzhou

\begin{tabular}{|c|c|c|}
\hline & Survey respondents ${ }^{\mathrm{a}}$ & $\begin{array}{l}\text { Residents of } \\
\text { Hangzhou } \\
\text { Metropolitan Area }\end{array}$ \\
\hline Proportion male/female (\%) & $\begin{array}{l}58.5 \text { female; } \\
41.5 \text { male }\end{array}$ & $\begin{array}{l}49.3 \text { female; } \\
50.7 \text { male }\end{array}$ \\
\hline Avg. no. persons per household & 2.79 & 2.84 \\
\hline $\begin{array}{l}\text { Avg. no. children aged } 0-6 \text { per } \\
\text { household }\end{array}$ & 0.134 & 0.169 \\
\hline $\begin{array}{l}\text { Avg. no. children aged } 7-17 \text { per } \\
\text { household }\end{array}$ & 0.341 & 0.360 \\
\hline Avg. age of respondents/interviewees & 42 & - \\
\hline $\begin{array}{l}\text { Proportion of workforce participants } \\
\text { among respondents/interviewees }\end{array}$ & 75.4 & 78.9 \\
\hline $\begin{array}{l}\text { Proportion of students/pupils among } \\
\text { respondents/interviewees }\end{array}$ & 2.7 & $\mathrm{n} / \mathrm{a}$ \\
\hline $\begin{array}{l}\text { Mean household income ( } 1000 \text { yuan } \\
\text { renminbi) }\end{array}$ & 45.3 & 53.3 \\
\hline $\begin{array}{l}\text { Proportion with university education ( } 4 \\
\text { years or more) }\end{array}$ & 11.2 & $\mathrm{n} / \mathrm{a}$ \\
\hline $\begin{array}{l}\text { Proportion of households having at least } \\
\text { one motor vehicle available for private } \\
\text { transport }\end{array}$ & 18.3 & $\mathrm{n} / \mathrm{a}$ \\
\hline $\begin{array}{l}\text { Proportion of households having at least } \\
\text { one e-bike available for private transport }\end{array}$ & 5.0 & $\mathrm{n} / \mathrm{a}$ \\
\hline $\begin{array}{l}\text { Proportion of households having at least } \\
\text { one car available for private transport }\end{array}$ & 6.1 & $18.87^{\mathrm{c}}$ \\
\hline
\end{tabular}

a $N=3155$; surveyed June 2005 .

b $N=4.09$ million; 2005 data unless indicated.

c 2007 data. 


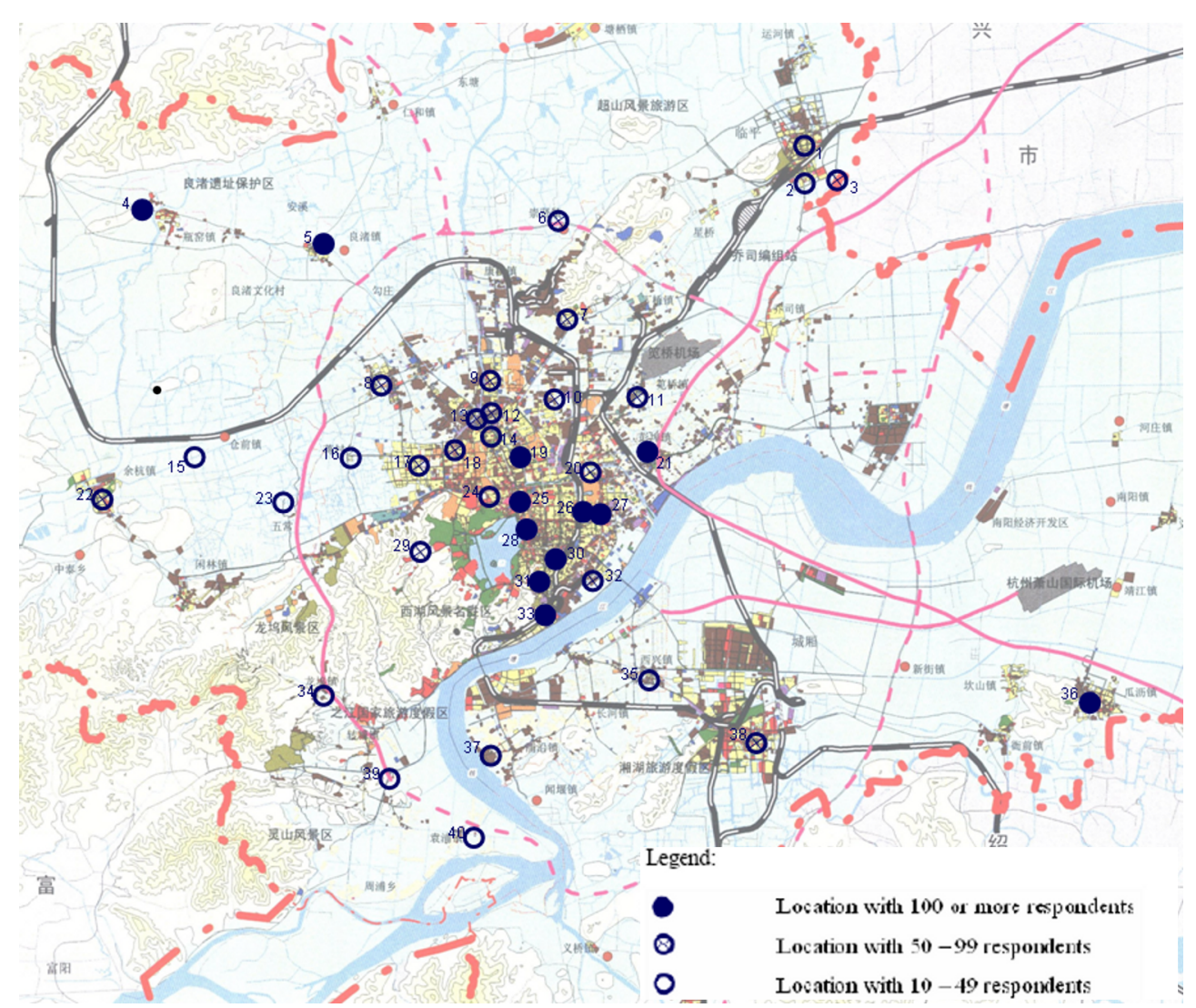

Figure 2: Locations of survey respondents' residences. Only locations with more than 10 respondents are shown in the figure. These locations include 2913 of the 3154 respondents (92.3\%). The remaining 242 respondents are distributed among 75 locations with numbers of respondents ranging from one to nine

\section{Typical Mobility Patterns In Different Parts Of The Metropolitan Area}

In the charts that follow, respondents are subdivided into four categories according to the distance from their residence to the center of Hangzhou. ${ }^{6}$ Figure $3(\mathrm{a})-(\mathrm{c})$ show how the average total daily traveling distance during the investigated week, the distance traveled by car/taxi, and the proportion of the total distance traveled by non-motorized modes vary according to the distance belt from the city center of Hangzhou wherein the respondents live. In all these figures, respondents who have not traveled at all during the relevant investigation period and respondents with extreme total traveling distances during the week have been excluded ${ }^{7}$. Except for

${ }^{6}$ The four distance belts have been defined in such a way that each belt includes approximately one-fourth (a quartile) of the total number of respondents.

${ }^{7}$ By extreme traveling distances we mean distances more than three interquartile ranges above the upper quartile (see Norusis 1990). 181 respondents with weekly traveling distances above $261 \mathrm{~km}$ were excluded according to this criterion, in addition to 41 respondents who had not traveled at all during the investigated week. On average, the respondents reporting extremely long traveling distances have a higher level of education and a higher income, and are more likely to own a car and hold a driver's license than the remaining respondents; a clear majority are men. They also live on average further away from the city center of Hangzhou $(12.4 \mathrm{~km})$ than the other respondents (9.0 km among those who have traveled non-extreme distances). On the other hand, respondents who have not 
travel by car/taxi, both arithmetic means and median values are shown; for travel by car/taxi, only arithmetic means are shown, as less than half the respondents within each distance belt has traveled by these modes, and the median values of travel by these modes are therefore zero in each distance belt.

We see a clear tendency toward shorter traveling distances among respondents who live close to the city center (Figure 3(a)). In particular, this applies to travel by car or taxi (Figure $3(\mathrm{c})$ ), where respondents living less than $3.4 \mathrm{~km}$ from the center of Hangzhou travel, on average, less than one-quarter of the average distance traveled by car/taxi among the remaining respondents. Respondents living close to the city center of Hangzhou also travel shorter distances by other motorized modes (bus and e-bike) than those living in peripheral areas. In contrast, the average traveling distance by non-motorized modes is about 20 percent greater among respondents living in the innermost distance belt than among the remaining respondents. As a result, non-motorized modes account for 70 percent of the distance traveled among the respondents living less than $3.4 \mathrm{~km}$ away from the city center of Hangzhou, compared to 43 percent among the remaining respondents (Figure 3(b)). The difference between the inner and the three remaining distance belts in the proportion of non-motorized travel is larger when comparing median values than when comparing arithmetic means. This indicates that there are some respondents in all distance belts who carry out a high proportion of their travel by nonmotorized modes. However, the median values show that this is much more typical among the residents of the inner distance belt than among the remaining respondents to carry out a very high proportion of weekly travel by bicycle or on foot.

These differences in travel behavior only reflect differences in income levels to a limited extent. Average income in the innermost distance belt is somewhat lower than in the other three belts, but these income differences are much smaller than the differences in travel behavior between the belts, particularly in regards to travel by car and taxi. Moreover, whereas income levels are lower in the two outer distance belts than in the second inner belt, the respondents of the two outer belts travel longer distances in total as well as by car.

\subsection{Are the differences merely a result of residential self-selection?}

Several researchers have pointed out that self-selection of residents into geographical locations matching their traveling preferences can be an obstacle to measuring the influences of residential location on travel. In order to throw light on the extent to which geographical differences in travel behavior are a result of residential self-selection, respondents were asked to select and pri-

traveled at all during the week also live further away from the city center of Hangzhou $(12.5 \mathrm{~km})$ than the average. These respondents do not differ much from the remaining respondents in terms of socioeconomic characteristics. Needless to say, all the respondents with extreme traveling distances used energy for their transport during the week. Their level of energy use is, however, not related to any of the residential location variables and is also only weakly related to some few socioeconomic variables. This reflects the high degree of randomness regarding the destinations and distances of the trips carried out by the respondents with extreme traveling distances during the week. To a large extent, extreme traveling distances represent trips to places outside the metropolitan area, e.g. work-related trips to meetings and other business activities in other cities. The fact that the respondents with extreme traveling distances do not show any countervailing tendency to the tendency found among those respondents with nonextreme traveling distances suggests that the exclusion of the former respondents from the analysis is hardly a source of biased results. The same applies to the non-travelers, who make up only 1.3 percent of the respondents and whose energy use is zero regardless of residential location. 


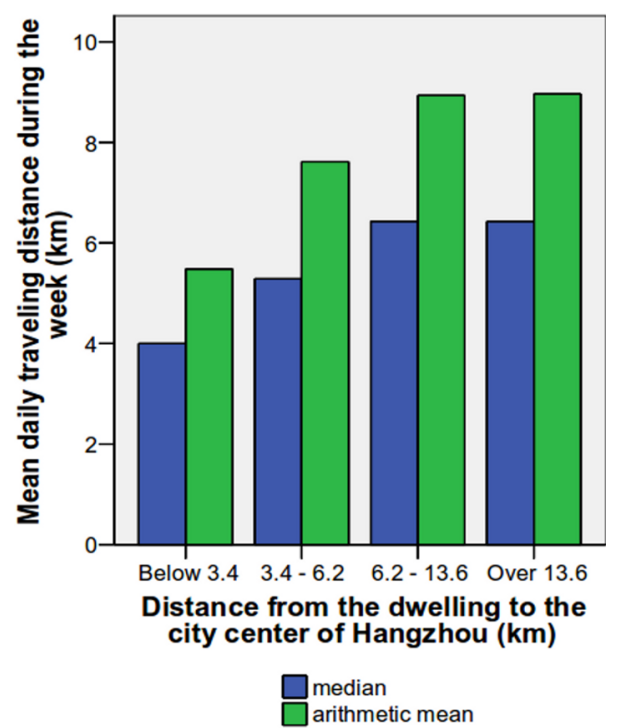

(a) Mean and median daily traveling distances during the whole week

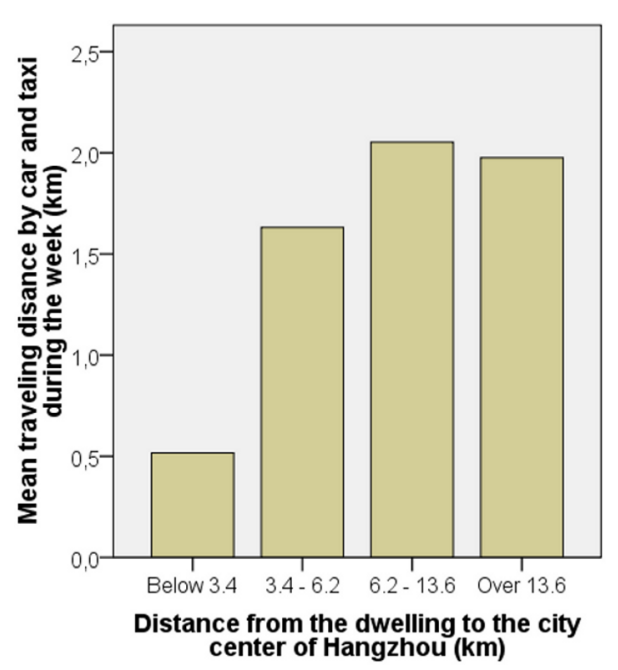

(c) Mean daily traveling distances by car and taxi during the whole week

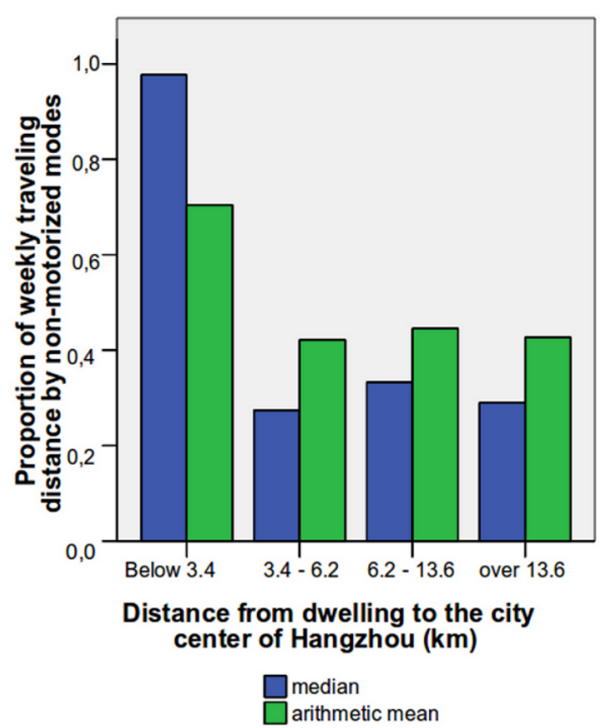

(b) Mean and median proportions of weekly traveling distances by non-motorized modes

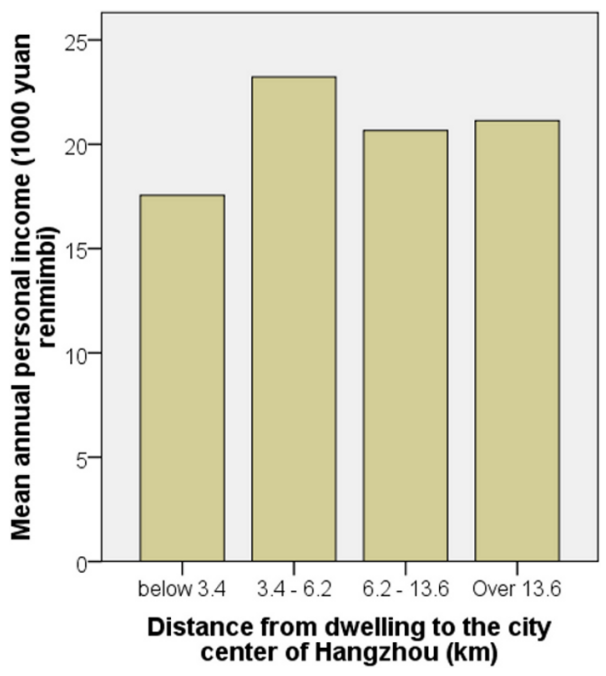

(d) Mean personal annual income

Figure 3: Key travel characteristics and income levels of individual respondents categorized according to residential distance from the city center

$N=2829$ for the three travel behavior variables, with $791,700,683$, and 655 respondents, respectively, in the innermost, second, third, and outermost distance belts. $N=2699$ for personal income, with 738, 666, 665, and 630 respondents, respectively, in the four distance belts. An additional 225 respondents with no travel or extreme traveling distances (above $37.2 \mathrm{~km}$ daily) have been excluded from all four analyses. 
oritize three out of 20 characteristics that would be most important if they were to move from their present residence to a new dwelling. Based on these answers, a dichotomous variable indicating whether or not the respondent showed a preference for residential locations enabling and facilitating shorter traveling distances and the use of public and/or non-motorized modes of travel was constructed. Respondents whose two highest-rated residential characteristics included "Short distance to the workplace", "Close to shopping facilities", "Close to rail station" or "Close to bus stop" were assigned a value of 1 , while the remaining respondents received a value of 0 .

Figure 4(a) shows that mean traveling distances by car are longer in the outer than in the inner parts of Hangzhou Metropolitan Area both among respondents mentioning and not mentioning proximity to public transport, workplace, and/or shopping opportunities among their two most important residential choice criteria. This suggests that travel-related residential selfselection plays a modest role, if any, as an explanation of geographical differences in travel behavior. According to Cao et al. (2009), stronger evidence of an effect of residential location independent of residential self-selection might accrue if the travel behavior of residentially dissonant respondents is found to be clearly different from that of consonant residents in the type of neighborhood in which the former would rather live. Dissonant residents are residents living at locations poorly matching their preferences, whereas consonant residents are those who live at locations where their residential preferences are met. In our contexts, respondents prioritizing proximity to public transport, employment, and/or shopping opportunities could be considered consonant if they live in the inner distance belt and dissonant if they live in the outer three distance belts (and especially in the two outermost belts). Conversely, residents who do not consider proximity to public transport, employment, and/or shopping opportunities important could be characterized as consonant if they live in the suburbs and dissonant if they live in the innermost distance belt. As Figure 4 shows, travel distances by car increase the further away from the city center of Hangzhou the residence is situated both among consonant ('match') and dissonant ('mismatch') residents. The difference between inner-city residents and respondents living in the outer three distance belts is particularly great among the consonant residents, as would be expected if travel behavior is (partly) influenced by transport-related residential self-selection. But there is also a clear center-periphery gradient in mean traveling distances by car among dissonant residents. Actually, respondents living less than $3.4 \mathrm{~km}$ from the city center who do not emphasize proximity to public transport, employment, or shopping opportunities among their prioritized residential choice criteria travel considerably less by car, on average, than respondents in any of the outer distance belts who do emphasize proximity to public transport, employment, and/or shopping as important criteria for their choice of residence. If self-selection was the main reason for geographical differences in the amount of travel by car, one would hardly expect to find such a pattern. In that case, we would expect to find the opposite relationship when comparing dissonant residents across the distance belts, i.e. less car travel among suburbanites who prefer proximity to transit, workplace and shopping than among inner-city dwellers who do not emphasize such residential characteristics. Given the fact that that the persons living in the outer belts have considerably poorer access to public transport or local services than their inner-city counterparts, this indicates a clear effect of residential location independent of residential self-selection. The possible influence of residential prefer- 
ences as well as a number of other attitudinal, socioeconomic and demographic variables will be addressed more comprehensively in the next section. ${ }^{8}$

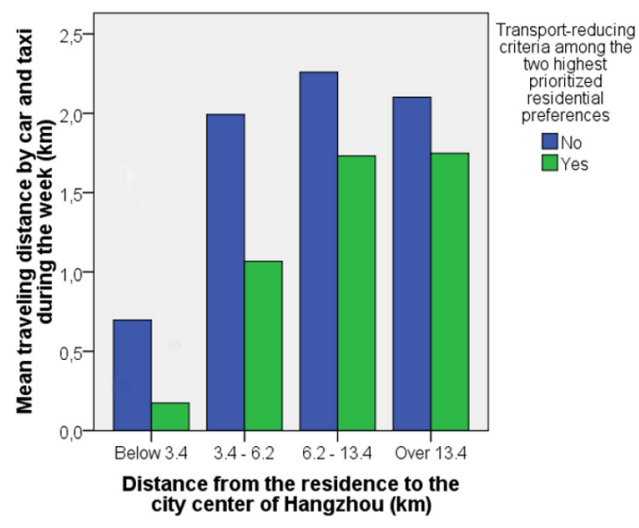

(a)

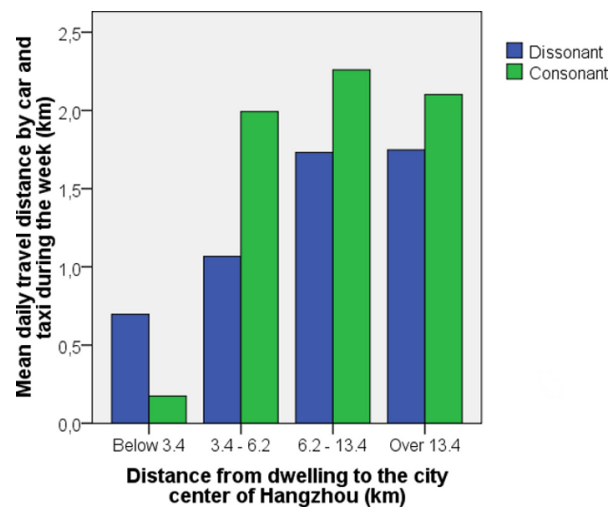

(b)

Figure 4: Traveling distances by car as a function of residential location and transport-related residential preferences

Mean daily travel distances by car over the week among respondents mentioning and not mentioning, respectively, proximity to public transport, employment, and/or shopping opportunities among their two most important residential choice criteria (a), and among dissonant (mismatch) and consonant (match) residents (b), living in different distance intervals from the city center of Hangzhou. $N=2829$ in total (1047 'yes' and 1782 'no'; 1537 'consonant' and 1292 'dissonant'), varying from 655 to 791 in the different distance intervals.

\subsection{Energy use}

Information about the respondents' traveling distances by different modes was used to calculate their energy use for transportation during the investigated week. ${ }^{9}$ As shown in Figure 5,

\footnotetext{
${ }^{8}$ For a comprehensive analysis of the extent to which residential self-selection represents a source of error in studies of land use-travel issues, see Næss (2009) and other articles in a special issue of the journal Transport Reviews.

${ }^{9}$ Here, only energy use for motorized travel has been included. The additional consumption of food and beverages required to compensate for the respondents' physical activity in connection with their trips by foot and by bike was considered negligible in this context. According to the Committee on the Future of Personal Transport Vehicles in China and others (2003, 247-248), cars in Shanghai have an average fuel efficiency rate of $10.7 \mathrm{~km}$ per liter of fuel (of which 14/15 is gasoline and $1 / 15$ is CNG/LPG), with an average occupancy of 2.5 persons. Given an energy content per liter of gasoline of approx. $9.6 \mathrm{kWh}$, average energy use per passenger $\mathrm{km}$ by car under Shanghai 2000 conditions is thus $9.6 /(10.7 \times 2.5) \mathrm{kWh}=0.359 \mathrm{kWh} /$ passenger $\mathrm{km}$. According to the same source, occupancy figures as well as energy use per vehicle $\mathrm{km}$ are likely to remain fairly constant during the period $2000-2020$. Wu (2008) operates with a higher energy use per passenger $\mathrm{km}$ by car $(600 \mathrm{kcal}$, corresponding to $0.698 \mathrm{kWh} /$ passenger $\mathrm{km}$ ). The latter source is a conference presentation, but I consider it to be reliable because the author is a renowned professor at Tsinghua University. Unfortunately, the research on which Wu's presentation was based seems to be available only in Chinese. In my calculations, I have chosen to use the average of the figures from the two above-mentioned sources, i.e. $0.528 \mathrm{kWh}$ per passenger $\mathrm{km}$ by car. I have used the same figure for taxi travel. According to $\mathrm{Wu}$ (2008), average energy use per passenger $\mathrm{km}$ by bus in Chinese cities is $172 \mathrm{kcal}$ and by train $49 \mathrm{kcal}$, corresponding to $0.200 \mathrm{kWh} /$ passenger $\mathrm{km}$ by bus and $0.057 \mathrm{kWh} /$ passenger $\mathrm{km}$ by train. I have used these figures as a basis for my calculations of energy use for public transport. Data on the energy use per kilometer
} 
respondents living in the most central distance belt used, on average, less than half the amount of energy for transport consumed by those living in the three outer distance belts. There are only small differences in energy averages between the three outer distance belts; energy use is slightly lower in the outermost belt than in the two middle belts, but still considerably higher than among the inner-city respondents. Interestingly, this tendency to reduced energy use among the most peripheral respondents is more evident when comparing median values than arithmetic means. This suggests that a relatively high proportion of the respondents who reside in the outermost peripheral areas (e.g. farmers) work and have their other daily destinations locally within walking or biking distance, while at the same time a considerable minority of the most peripheral residents travel long distances, notably to workplaces in the city of Hangzhou. On the other hand, the median energy use is zero among the respondents living less than 3.4 $\mathrm{km}$ from the city center of Hangzhou. This implies that more than half of the respondents of the innermost distance belt did not travel by any motorized mode during the entire week of investigation.

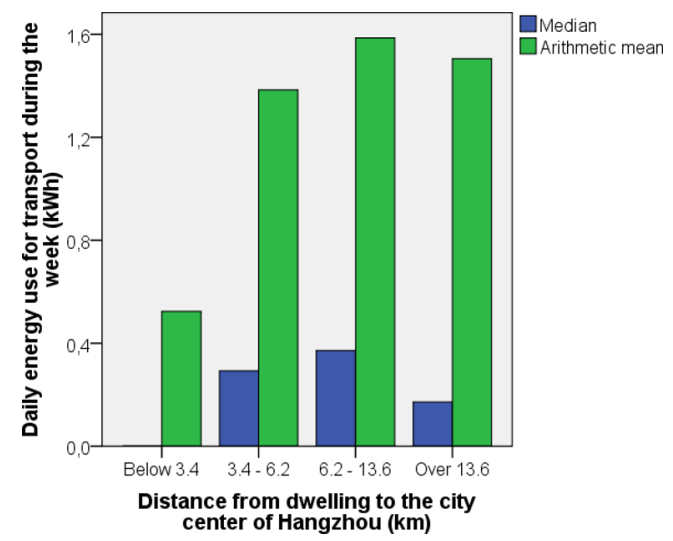

Figure 5: Mean and median daily energy use during the investigated week among respondents living within different distance belts from the city center of Hangzhou

$N=2829$, with 791, 700, 683, and 655 respondents, respectively, in the innermost, second inner, second outer, and outermost distance belt. 222 respondents with zero or extreme weekly traveling distances (above $262 \mathrm{~km}$ ) have been excluded from the analysis.

\section{Multivariate Statistical Analyses}

The graphs shown in the previous section have provided some preliminary indications about relationships between the location of residences within the metropolitan urban structure and the travel behavior of the residents. However, in order to distinguish differences in travel behavior caused by residential location from differences caused by individual characteristics of the

traveled by electric bike were obtained from Weinert et al. (2006). According to this source, average energy use per passenger $\mathrm{km}$ by e-bike is $0.014 \mathrm{kWh}$. Compared to a European context, my Chinese energy data imply lower energy use per passenger $\mathrm{km}$, especially by train but also by bus and to some extent by car. For comparison, figures from the Copenhagen Metropolitan Area show $0.64 \mathrm{kWh} /$ passenger km by car, $0.32 \mathrm{kWh} /$ passenger $\mathrm{km}$ by bus, and $0.19 \mathrm{kWh} /$ passenger $\mathrm{km}$ by train. A higher degree of capacity utilization (more crowded buses and trains in China) is probably the main explanation of these differences. 
residents, it is necessary to conduct a statistical control for the influence of factors other than dwelling location, i.e. to "keep constant" all factors of influence apart from those whose effects we wish to examine. In our analyses, we have included most of the variables mentioned in the scientific literature as potential sources of false inferences from the immediate (non-controlled) relationships between urban structure and travel. Appendix A provides an overview of the various independent variables, their assumed ${ }^{10}$ influences on travel behavior, and (for the control variables) the reasons why we have considered it appropriate to include the variable in the analysis.

The following three urban structural variables were included in the multivariate analyses:

- The location of the dwelling relative to the city center of Hangzhou ${ }^{11}$

- The location of the dwelling relative to the closest second-order center. ${ }^{12}$

- The location of the dwelling relative to the closest third-order center (the town centers of Yuhang (West), Liangzhu, Tangxi, Yipeng, Guali or Linpu. ${ }^{13}$

These urban structural variables were chosen from theoretical considerations as well as iterations based on preliminary analyses of the empirical data. For all three variables, the distances measured in kilometer were transformed by means of non-linear functions. The location of the dwelling relative to the city center of Hangzhou tells something about the situation of the residence relative to the concentration of workplaces and service facilities found in the city of Hangzhou, especially in its inner and central parts. The closer to this concentration respondents live, the easier it will be for them to find a workplace matching their qualifications within a short distance from the dwelling, and the shorter will be the distances to special commodity shops and number of cultural and entertainment facilities. On the other hand, if the distance to the city center of Hangzhou is too long, many residents will prefer more local job opportunities and service facilities even if these jobs and services are, apart from the traveling distances,

\footnotetext{
${ }^{10}$ From theoretical or common-sense considerations, supplemented with information from the qualitative interviews.

${ }^{11}$ Based on theoretical considerations as well as preliminary iterative analyses of the empirical data, the location of the residence relative to the city center of Hangzhou was measured by means of a variable constructed by transforming the linear distance by means of a non-linear function. This function was composed of a hyperbolic tangential function and a quadratic function, calculated from the following equation: $M=((\exp (d \times 0.3-0.3))-$ $\exp (-(d \times 0.3-0.3))) /(\exp (d \times 0.3-0.3)+\exp (-(d \times 0.3-0.3)))-(0.00007 \times(d-40) \times(d-40))$, where $M$ is the transformed distance from the dwelling to the city center of Hangzhou and $d$ is the linear distance, measured in kilometers. The linear distance was normally measured "as the crow flies," but without crossing lakes or continuous natural areas with no roads. Given a positive relationship between the transformed function and the traveling distance, this function describes a situation where traveling distances increase quite rapidly as the distance from the dwelling to the city center increases from zero up to some $6 \mathrm{~km}$, then less steeply until a level where traveling distances increase only very slightly as the distance from the residence to the city center increases beyond some 10 $\mathrm{km}$.

${ }^{12}$ Like the location of the dwelling relative to the city center of Hangzhou, the linear distance from the dwelling to the closest second-order center was transformed by means of a non-linear function; in this case a hyperbolic tangential function. For details, see Næss (2007).

${ }^{13}$ Like the location of the dwelling relative to the closest second-order center, the linear distance from the dwelling to the closest third-order center was transformed by means of a hyperbolic tangential function. For details, see Næss (2007).
} 
less attractive than the central ones. The relationship between traveling distances and the distance between the residence and downtown Hangzhou is therefore not likely to be linear, but could rather be expected to follow a curve reflecting a lower propensity to use facilities in the city of Hangzhou when living in the peripheral parts of the metropolitan area.

The location of the dwelling relative to the closest second-order and third-order centers tells something about the accessibility of local concentrations of job opportunities and services. Here, too, 'distance decay' in the form of lower propensity to use facilities in a second- or thirdorder center when living far away from such a center could be expected. The 'catchment areas' of the lower-order centers, i.e. the areas from which they draw a large proportion of commuters, customers, visitors to service facilities, etc., are of a limited size. The distances from the dwelling to these centers could therefore be expected to influence the amount of travel within a relatively narrow zone around the lower-order centers. Beyond this zone, traveling patterns are not likely to be influenced by further increase in the distance from the dwelling to a lower-order center.

In addition to the three above-mentioned urban structural variables, the regression model included the following 18 demographic, socioeconomic, attitudinal and other non-urban-structural variables ${ }^{14}$.

- Demographic variables: sex; age; number of children younger than seven years of age in the household; number of children aged 7-17 in the household; number of adult persons in the household.

- Socioeconomic variables: education level; personal income; car ownership; driver's license for car; whether or not the respondent is a workforce participant; whether or not the respondent is a student.

- Attitudinal variables: attitudes to transport issues; attitudes to environmental issues; transport-related residential preferences. ${ }^{15}$

\footnotetext{
${ }^{14}$ The 21 independent variables included in the multivariate analyses might appear to be a quite high number, possibly leading to so-called multicollinearity problems (unreliable statistical analyses because of too-strong mutual correlations between some of the independent variables). However, formal collinearity diagnostics do not indicate any such problems. With all 21 independent variables included in the regression model, the three residential location variables have the following tolerance levels: location of the residence relative to downtown Hangzhou, 0.76; location of the residence relative to the closest second-order center, 0.89 ; location of the residence relative to the closest third-order center, 0.91 . None of the 21 independent variables have tolerance levels below 0.53 . According to Lewis-Beck $(1980,60)$, problems of high multicollinearity exist if any of the variables of the regression model has a tolerance level "close to zero." Given the fact that the theoretical range of tolerance levels is from 0 to 1 , the tolerance levels of the urban structural variables as well as the non-urban structural variables must be considered clearly satisfactory.

${ }^{15}$ Indices for attitudes to transport issues and to environmental issues were each based on seven separate questions. The respondents were asked to indicate the extent to which they agreed or disagreed to the statements about transport or environmental issues presented in each question, ticking for the relevant alternative on a five-level Likert scale. The answer alternatives were: Strongly agree; Agree to some extent; Indifferent; Disagree to some extent; Strongly disagree. Some of the statements regarding transport issues expressed a positive and some a negative attitude to car travel. Similarly, some of the statements about environmental issues expressed a positive and some a negative attitude to prioritizing the environment over other concerns. Values of the separate variables from which the indices were calculated were coded in such a way that high index values indicated, respectively, car-oriented transport attitudes and a strong concern for environmental protection. The residential preference variable is the same one as described in the paragraph on self-selection in Section 4.
} 
- Other non-urban-structural variables indicating particular activities, obligations or circumstances that may influence traveling distances: whether or not the respondent had moved to her/his present dwelling less than five years ago; regular transport of children to/from kindergarten or school; whether or not the respondent traveled outside the Hangzhou Metropolitan Area during the week of investigation; whether or not the respondent stayed overnight away from home four or more nights during the week of investigation.

Below, we shall focus on the influences of residential location on total traveling distances, the share of non-motorized travel, and energy use for transport. Main results from the remaining statistical analyses (including commuting distances and traveling distances by different modes, with separate analyses for weekdays and weekends and for different population groups) are available in Næss (2007).

\subsection{Total traveling distances}

Table 2 shows the results of the multivariate analysis of factors potentially influencing the respondents' average daily traveling distance during the whole investigated week. According to our material, the daily traveling distance during the week as a whole is influenced by one urban structural variable: the location of the dwelling relative to the city center of Hangzhou. ${ }^{16}$ Traveling distances tend to increase the further away from the city center of Hangzhou the dwelling is located. Controlling for demographic, socioeconomic, and attitudinal factors and for particular activities, obligations, or circumstances, average traveling distances are nearly oneand-a-half times greater among respondents living more than $10 \mathrm{~km}$ away from the city center of Hangzhou than among respondents living closest to the city center (Figure 6a). When the distance between the residence and downtown Hangzhou increases beyond some $10 \mathrm{~km}$, the effect on traveling distances from this additional increase is very modest. ${ }^{17}$ This effect is in accordance with what could be expected from theoretical considerations and is also in line with

\footnotetext{
${ }^{16}$ Here, traveling distances have been measured as the actual distances traveled. Respondents with extreme mean travel distances (above $37.2 \mathrm{~km}$ daily) have been excluded. In addition, a number of respondents failed to provide information about traveling distances and/or to answer other questions on the questionnaires. The number of respondents on which the tables $2-5$ and figures 6 and 7 are based is therefore lower than the number of respondents whose travel distances meet the above-mentioned criteria. In spite of the exclusion of respondents with extreme values, the distribution of traveling distances deviates somewhat from normality (mean 7.70, median 5.29, skewness 1.684 and kurtosis 2.705 ). If logarithmically transformed traveling distances are used in the analysis, the distribution is closer to normality (mean 0.694 , median 0.724 , skewness -0.671 and kurtosis 0.802 ). Including the same independent variables in the model, the effect of residential location relative to downtown Hangzhou increases $(\beta=0.153, p=0.0000)$, and we also find an effect of the location relative to the closest second-order center $(\beta=-0.055, p=0.0070)$. The latter effect is negative, indicating that respondents living close to a third-order center travel somewhat longer than their counterparts living in more rural areas at the same distance from downtown Hangzhou, other things equal.

${ }^{17}$ As mentioned in Note 11, the transformation of the simple distance to downtown into a non-linear distance function was based on an iterative process in which different functions (including cubic, quadratic, hyperbolictangential, and a combination of the latter two) were tried out, as well as different parameter values of each of these functions. The chosen transformation was the one showing the highest goodness of fit. A model where the chosen transformation was replaced with the simple linear distance to downtown showed a considerably lower goodness of fit.
} 
findings in a number of other cities, including the Copenhagen Metropolitan Area (Næss 2005, 2006a,b).

The observed influences of variables other than residential location are in line with expectations. Traveling distances tend to increase if the household has a car at its disposal, if the respondent holds a driver's license for car, is male, has a high income, is young, or has moved to the present dwelling less than five years ago. It is hardly surprising that the traveling distance also tends to increase if the respondent has been outside Hangzhou Metropolitan Area during the week of investigation. On the other hand, having stayed overnight away from home four or more nights during the investigation period tends to contribute to reduced traveling distances.

Not surprisingly, availability of a private car in the household shows a clear influence on traveling distances. Owning a car increases people's ability to travel around and can lead to an expansion of the geographical area within which job opportunities are sought as well as to more frequent and longer non-work trips. Holding a driver's license also increases the possibility of car travel and hence expands the respondents' potential radius of action. However, it should be noted that automobile ownership (and perhaps also possession of an automobile driver's license) may itself be influenced by the location of the dwelling relative to relevant trip destinations. In order to carry out the daily program of activities within time-geographical constraints (Hägerstrand 1970), suburbanites may consider it necessary to purchase a (second) car, whereas their inner-city counterparts, living closer to their daily destinations, are much less likely to feel compelled to travel by fast modes of transportation. Including car ownership among the control variables, as done in our multivariate models, therefore arguably leads to a certain underestimation of the influences of residential location on travel behavior. ${ }^{18}$

A high income also increases average travel distances by enhancing people's ability to pay for public transport, motor vehicles, and fuel. The effect of income may also mirror situations where a high salary has made respondents willing to accept longer commuting distances than they would otherwise. The effect of gender is in line with findings in several European studies and probably reflects inequalities between women and men in access to vehicles, as well as a traditionally more local job market orientation among females (see Hjorthol 2000 and Næss 2008 for a further discussion). The effect of having moved partly reflects situations where innercity residents have moved to suburban dwellings located farther from their jobs, and partly a wish among recent movers to visit friends and relatives near their previous residences. ${ }^{19}$

We also find a tendency to longer traveling distances among respondents with car-oriented transport attitudes, but this effect is modest $(\beta=0.045, p=0.0309)$. Interestingly, neither of the two other attitudinal variables (residential preferences and environmental attitudes) show any effect whatsoever on traveling distances ( $p=0.989$ and 0.809 , respectively).

The effect of having stayed overnight away from home more than half of the week is more difficult to explain. Many of those who have stayed overnight away from home have been outside Hangzhou Metropolitan Area. But as the impact of having been outside the metropolitan area has already been accounted for, the effect of overnight stays away from home refers to overnight stays within the region. It is possible that some respondents stay at factory dormitories or with friends and relatives living close to their workplaces during the weekdays, and thus they may travel less.

\footnotetext{
${ }^{18}$ For a further discussion, see Næss (2006b) chapter 8 and Næss (2009).

${ }^{19}$ See Yang (2006) for similar evidence from Beijing.
} 


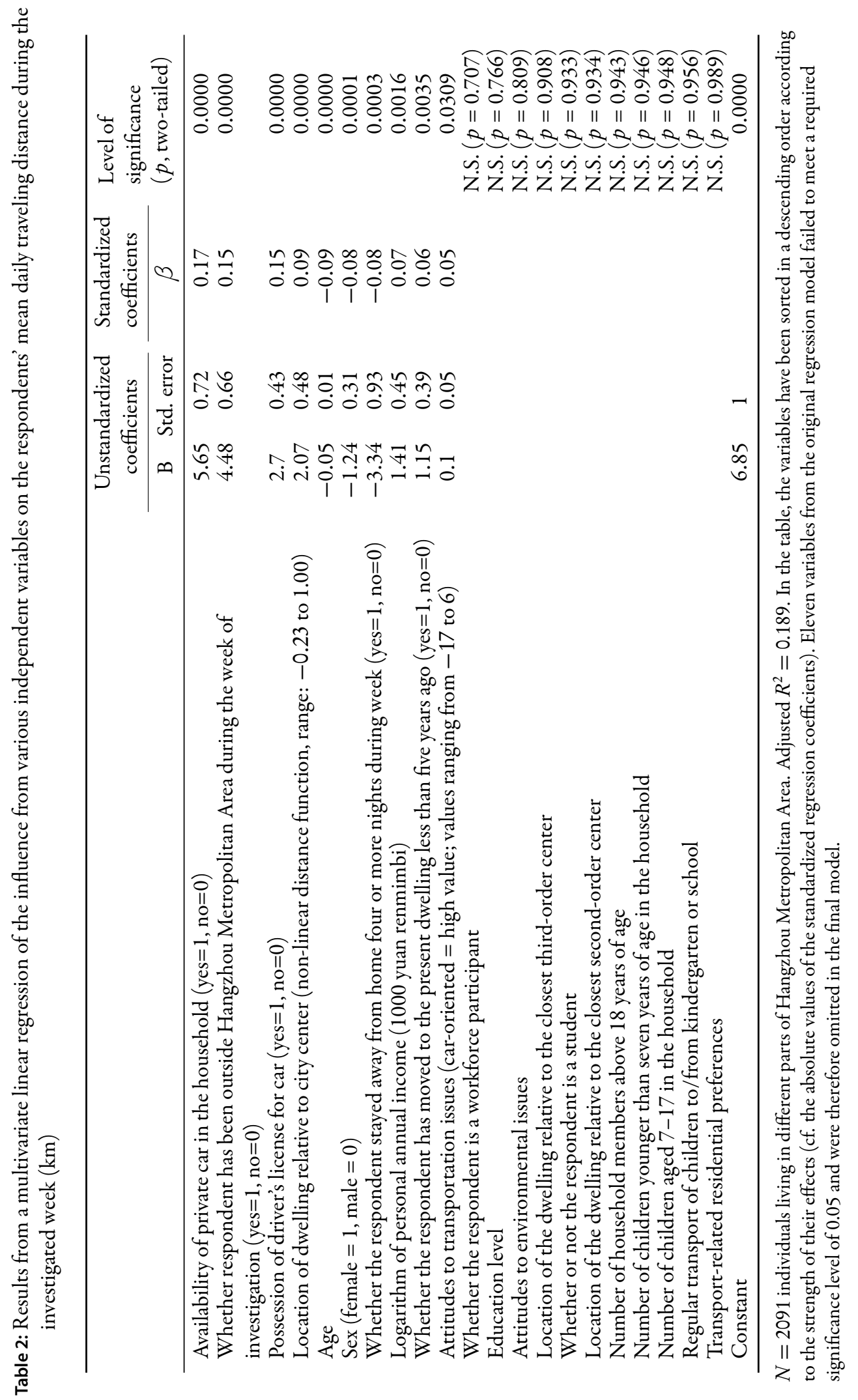




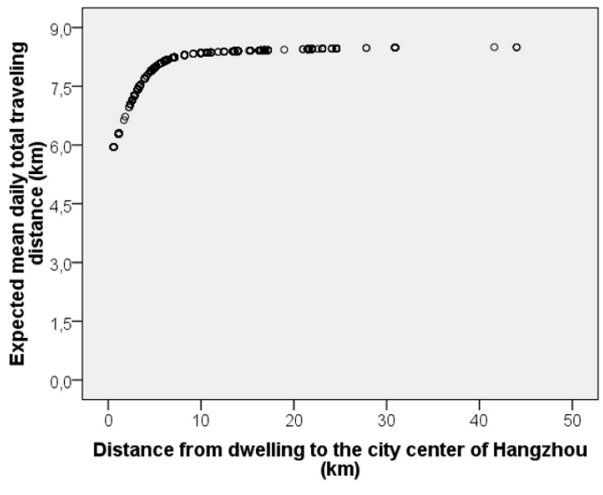

(a)

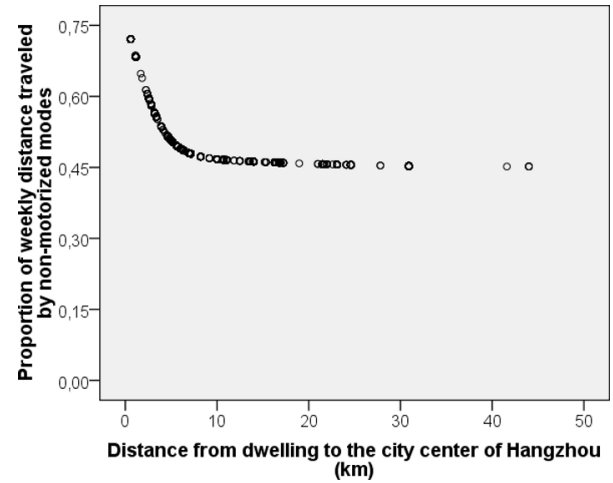

(b)

Figure 6: Expected daily total traveling distance (a) and proportion of distance traveled by nonmotorized modes (b) among respondents living at different distances from the city center of Hangzhou

$N=2091, p=0.0000$ for total traveling distance; $N=2212, p=0.0000$ for share of non-motorized travel.

\subsection{Non-motorized proportion of total traveling distance}

Table 3 shows the results of the multivariate analysis of factors influencing the non-motorized proportion of the respondents' traveling distances during the week. When controlling for other investigated potential factors of influence, the location of the dwelling relative to the city center of Hangzhou is the variable exerting the strongest influence of all on the proportion of weekday traveling distance carried out by bike or by foot $(\beta=-0.165, p=0.0000)$. The closer to the city center the respondents live, the higher their proportion of travel on foot and/or by bicycle tends to be. As can be seen in Figure 6(b), the expected proportion of the traveling distance carried out by foot or by bicycle is as high as 72 percent among the respondents living closest to the city center. Among respondents living more than $10 \mathrm{~km}$ from the city center, the expected share is around 45 percent, with slightly higher figures among those living around $10 \mathrm{~km}$ from the city center than among those living in the most remote locations. The expected proportion of travel on foot or by bicycle increases sharply when the distance from the residence to the city center of Hangzhou decreases below 5-6 km.

The location of the residence relative to the closest second- or third-order center does not show significant influence on the proportion of walk/bike travel.

Among the non-urban-structural variables, we find expected effects of car ownership, income, transport attitudes and possession of driver's license; respondents belonging to a household with a car, receiving a high income, holding car-oriented attitudes and/or holding a driver's license tend to carry out a lower proportion of their weekday travel by non-motorized modes than the remaining respondents. The proportion of pedestrian and bicycle travel also tends to be reduced if the respondent has a high education level, if there is more than one adult person in the household, and/or if the respondent has been outside the metropolitan area during the investigated week. The effect of belonging to a household including other adult members than the respondent may reflect the fact that it is more difficult for couples with specialized work qualifications than for single persons to adjust the locations of the workplace and residence in 
such a way that commuting distances are kept moderate. The two final effects (of education level and age) are a little more difficult to explain. It is probable that those with a high education have a lower possibility of finding a workplace within bicycling distance (especially if they live in suburbs or outer parts of the metropolitan area). Older persons include pensioners who do not need to commute out of the local neighborhood, and this may explain the higher share of non-motorized travel among older people.

\subsection{Energy use for transport}

A relatively high proportion of the respondents (36\%) did not use any motorized modes of transport during the week, and their energy use was accordingly recorded as zero. This implies that the ideal requirement of ordinary least square regression analysis of normally distributed dependent variables is far from met. In order to cope with this deviation from the ideal requirements of regression analysis, we have, in line with the so-called sample selection method, carried out the analysis of energy use by different modes in two steps. First, a binary logistic regression analysis was carried out in order to identify factors influencing whether or not the respondents had undertaken any travel by motorized modes and hence used energy for this purpose. This analysis included the construction of a Heckman selection bias control factor (LAMBDA). This control factor was then added to an ordinary least squares regression analysis of variables influencing the respondents' weekly energy use for transport. ${ }^{20}$ Control for selection bias was carried out according to the procedure described by Smits $(2003,5-7)$. In both analyses, respondents who did not travel at all during the investigation period were omitted. In the analysis of variables influencing the amount of energy used for transport, respondents who reported extreme total travel distances during the week (cf. note 8 ) have also been excluded.

Table 4 shows the results of the multivariate logistic regression analysis of factors potentially influencing the likelihood of having used energy for motorized travel during the investigated week.

Table 5 shows the results of the multiple ordinary linear regression analysis of factors potentially influencing the amount of energy use.

\footnotetext{
${ }^{20}$ The logistic and the ordinary least square analyses were themselves carried out in two steps. First, a number of variables with non-significant relationships with energy use $(p>0.050)$ were eliminated, using a backwardelimination method starting with a full model (20 or 21 independent variables) and running repeated regressions where the variable with the weakest level of significance in the previous regression was each time eliminated. This procedure went on until only variables meeting a significance level of 0.05 remained in the model. Thereupon, in order to keep the number of respondents included in the analysis as high as possible, the analysis was run once again with only the significant variables. Several respondents had missing values on the variables that turned out to have insignificant relationships with energy use and these respondents were excluded from the first step of the backwardelimination analysis even if they had valid values on all the remaining variables. Using this two-step procedure kept the number of respondents as high as possible in the final analysis. A transformation into logarithmic energy values was considered because the "raw" energy use values showed a skewed distribution, also among the respondents who had actually used motorized modes of transport during the investigated week. Using logarithmic energy values, the distribution was close to normality. However, the mean predicted value based on the logarithmically transformed energy figures turned out to deviate considerably from the actual mean. Using ordinarily measured energy figures, no such deviation occurred. The analysis was therefore finally carried out without logarithmic transformation of the energy values.
} 


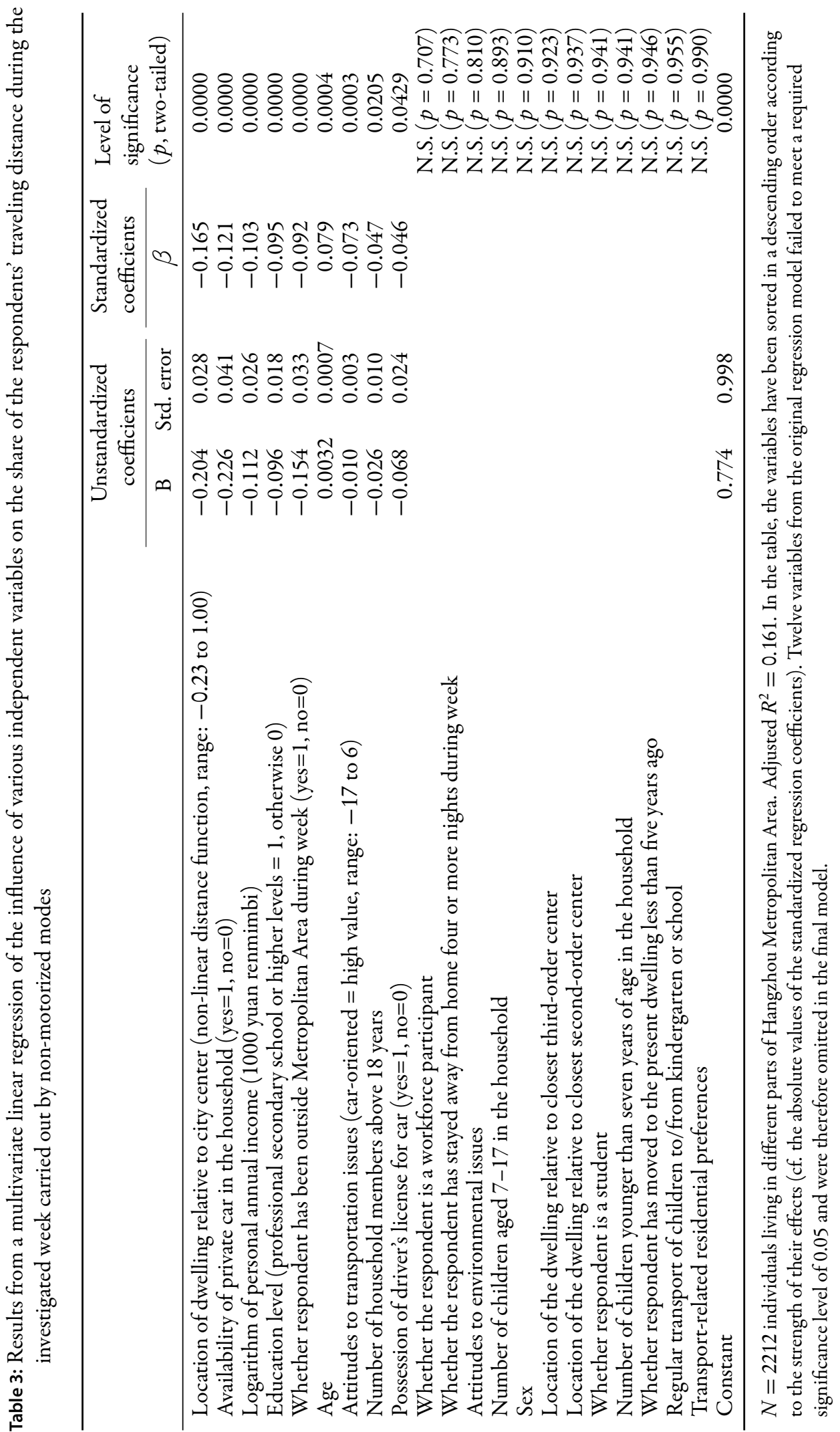




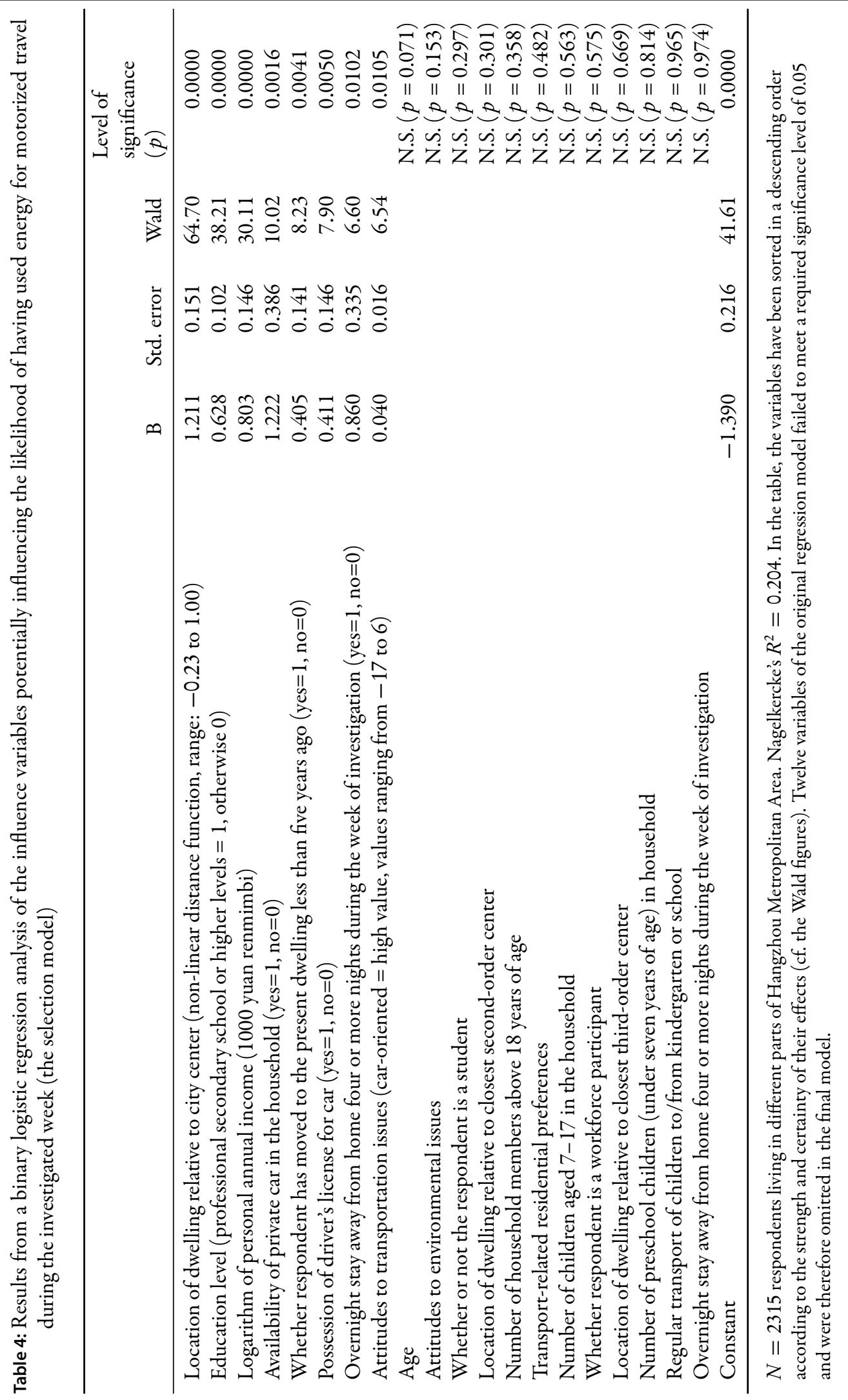




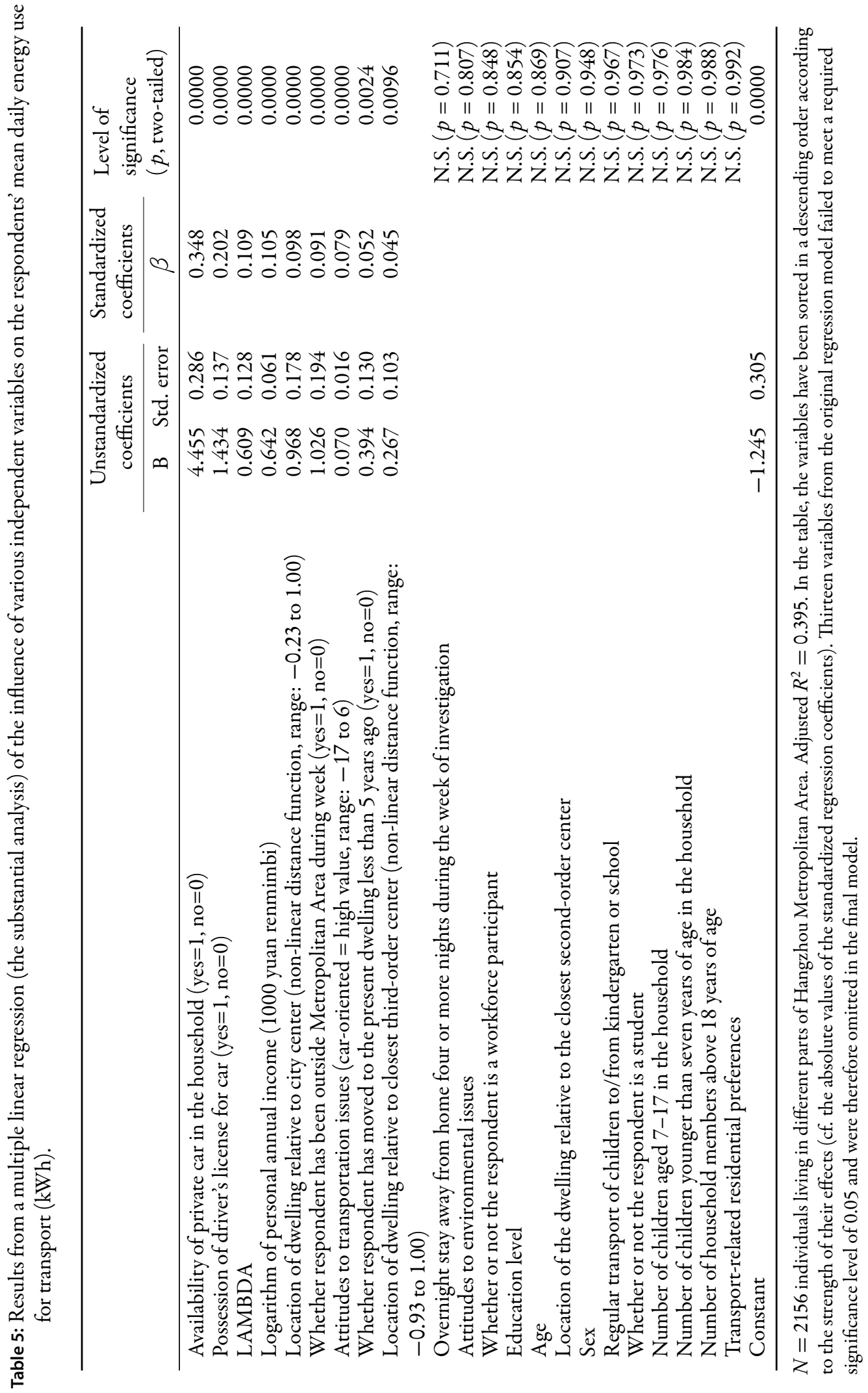


Based on the results shown in Table 5, predicted energy use depending on the distance from the dwelling to the city center of Hangzhou has been calculated. The results of this calculation are shown in Figure 7.

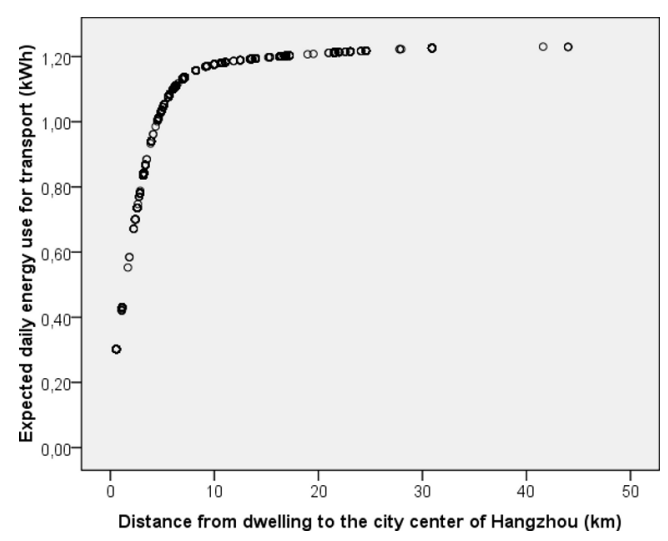

Figure 7: Expected daily energy use for transport among respondents living at different distances from the city center of Hangzhou $(N=2156)$

According to our data, respondents living more than $10 \mathrm{~km}$ from the center of Hangzhou could be expected to use about four times the amount of energy for transport within the metropolitan area as respondents living closest to the downtown area. First and foremost, this reflects a considerably higher propensity among inner-city dwellers to undertake all their travel during the week by non-motorized modes (cf. Table 4). Those who have traveled by motorized modes also tend to use slightly more energy the further away from downtown Hangzhou they live, but this effect is much more modest. A separate analysis among the users of motorized modes (not shown here) reveals weak tendencies of increasing energy use the further away the respondents live from the closest second-order and third-order center. However, none of the latter urban structural variables show any effect on the propensity of being a user of energy for motorized travel. Seen together, the location of the residence relative to the city center of Hangzhou therefore exerts a much stronger influence on energy use for transport than the location relative to lower-order centers.

Among the non-urban structural variables, energy use appears to be influenced particularly strongly by availability of a private car in the household, income, and possession of a driver's license. Other factors affecting energy use include whether or not the respondent has been outside Hangzhou Metropolitan Area during the week of investigation, transport attitudes, and whether or not the respondent has moved to the present dwelling during the latest five years. Energy use for transport tends to increase if the household has a car at its disposal, if the respondent holds a driver's license, if the respondent's income level is high, if the respondent has car-oriented transport attitudes, and/or if the respondent has moved to the present dwelling less than five years ago. Neither of these effects is surprising, cf. the discussions in connection with Tables 1 and 2. The Lambda factor reflects the effect of all the unmeasured characteristics related to the residential choice/transport decision. The coefficient of this factor therefore captures the portion of the effect of these characteristics that is related to energy use for transport (Smits 2003, 3). 


\section{Concluding Remarks}

The results of the Hangzhou Metropolitan Area study are well in accordance with the conclusions from studies in Paris (Fouchier 1998; Mogridge 1985), London (Mogridge 1985), New York and Melbourne (Newman and Kenworthy 1989), San Francisco (Schipper et al. 1994), Oslo (Næss et al. 1995), Dutch urban regions (Schwanen et al. 2001), English cities (Stead and Marshall 2001), Danish provincial cities (Hartoft-Nielsen 2001; Nielsen 2002; Næss and Jensen 2004), the Copenhagen Metropolitan Area (Næss 2005, 2006a,b), and Santiago de Chile (Zegras 2010). The results thus seem to be of a high generality, indicating that the dominant mechanisms by which residential location influences urban travel will be present across city sizes and despite considerable contextual differences.

Admittedly, some previous studies have concluded that only weak relationships or no relationship at all exist between urban structural characteristics is weak or entirely absent (see discussion in Williams et al. 2000). However, the majority of empirical studies concluding that urban structure has no significant influence on travel behavior have investigated other aspects of travel (e.g. trip frequencies or travel time) and/or focused on urban structural conditions other than those which, according to our investigations, exert the strongest influences on traveling distances and modal split (e.g. details of neighborhood design). Moreover, many of the publications from the above-mentioned studies omit theoretical discussion of the reasons why urban structure could be expected to influence travel, which characteristics of the urban structure could be expected to exert the strongest influence on travel behavior, and which aspects of travel behavior could be expected to be influenced by urban structure. Among theoretically informed, empirical, multivariate investigations into the influences on travel from the location of residences within the urban area, the converging conclusion is that living close to the city center does contribute to reductions in both traveling distance and automobile use.

Notably, the Hangzhou Metropolitan Area study also shows clear effects of residential location on traveling distances, modal split, and energy use when controlling for transport attitudes, environmental attitudes, and transport-related residential preferences. The differences in travel behavior between suburbanites and inner-city residents thus cannot be explained by self-selection of residents into neighborhoods matching their travel preferences.

The results of the Hangzhou Metropolitan Area study show that China must avoid urban sprawl if it is to prevent an uncontrolled increase in motorized daily-life travel. In general, accommodating growth in the building stock by means of densification instead of outward expansion is preferable from a transport energy point of view. In particular, densification close to the main center of the urban region can be expected to help reduce the total amount of travel and to increase the proportion of non-motorized travel. To some extent, densification close to the centers of second- or third-order towns may also produce favorable effects; however, our analyses show that the gains in terms of access to services and workplaces locally is countered by a higher tendency among respondents living close to lower-order centers to make long commutes to workplaces in the inner areas of Hangzhou. ${ }^{21}$ This may reflect a tendency among mobile, ed-

\footnotetext{
${ }^{21}$ Whereas residential location close to downtown Hangzhou contributes to a significant reduction in commuting distances $(\beta=0.258, p=0.0000)$ and a similar but weaker effect is found for proximity to one of the two second-order centers $(\beta=0.120, p=0.0003)$, location of the dwelling close to one of the six third-order centers tends to increase the length of journeys to work $(\beta=-0.188, p=0.0000)$. See Næss $(2007,246-251)$.
} 
ucated people working in Hangzhou to settle in third-order centers in order to live in a more rural setting and perhaps in a single-family house while still enjoying proximity to local services.

Compared to the level of affluence among the inhabitants, the present urban form of Hangzhou Metropolitan Area may be considered largely favorable from the perspective of environmentally sustainable transport. Admittedly, the locations and densities of some recently developed areas (notably the so-called economic and technological developmental zones) are less than favorable to minimizing energy use for transport. However, on average Hangzhou is still a dense city, and most of the outward urban expansion that has taken place in Hangzhou and in the second-order towns has been characterized by fairly high densities, and as such is very different from the one-story single-family home development so typical for urban expansion e.g. in many American cities.

Perhaps the challenge for the Hangzhou Metropolitan Area (and other similar Chinese urban areas) is not to make the built-up areas even denser than they are already (although such density increases may also be relevant, in particular in the most central parts of the city), but first and foremost to avoid adopting the low-density, sprawling form that was typical of development in American (and, in a more moderate form, European) urban regions during the second half of the twentieth century.

\section{Acknowledgments}

The author would like to thank the Zhejiang University members of the research team: Professor Yin Wenyao, Ma Weihong, Yao Yinmei, Li Fen, and especially Yan Hui, who played a key role in carrying out the questionnaire survey. Thanks also to Henrik Lolle at Aalborg University for advice in connection with the final statistical analyses, and to the anonymous referees of JTLU.

\section{References}

Cao, X., P. L. Mokhtarian, and S. L. Handy. 2009. Examining the impacts of residential selfselection on travel behaviour: A focus on empirical findings. Transport Reviews, 29(3):359 - 395. doi: 10.1080/01441640802539195.

Cheng, Y. 2004. Spatial-Temporal Distribution Analysis of Large-Scale Retail Stores. Case study in Wuban, China. Master's thesis, International Institute for Geo-Information Science and Earth Observation., Enschede, the Netherlands. URL http://www.itc.nl/library/papers 2004/msc/upla/cheng_yuanyuan.pdf.

Committee on the Future of Personal Transport Vehicles in China and others. 2003. Personal Cars in China. Washington, D.C.: The National Academies Press.

Fouchier, V. 1998. Urban density and mobility in Ile-de-France region. In Proceedings of the Eighth Conference on Urban and Regional Research. Madrid: UN/ECE-HPB and Ministerio de Fomento.

Hartoft-Nielsen, P. 2001. Boliglokalisering og transportadferd. (Residential location and travel behavior). Horsholm: Forskningscenteret for skov og landskab. 
Hjorthol, R. 2000. Same city, different options: An analysis of the work trips of married couples in the metropolitan area of Oslo. Journal of Transport Geography, 8:213-220.

Hägerstrand, T. 1970. Urbaniseringen af Sverige - en geografisk sambällsanalys (The urbanization of Sweden - a geographical analysis of society). Stockholm: Stockholm.

Jones, P. 1978. Destination choice and travel attributes. In D. Hensher and Q. Dalvi, eds., Determinants of travel choice, pp. 266-311. England: Saxon House.

Lewis-Beck, M. S. 1980. Applied Regression: An Introduction. Number 07-022 in Quantitative Applications in the Social Sciences. Newbury Park, London, and New Delhi: Sage Publications.

Lloyd, P. and P. Dicken. 1977. Location in space - A theoretical approach to economic geography. London: Harper \& Row.

Mogridge, M. 1985. Transport, land use and energy interaction. Urban Studies, 22(6):481-492. doi: 10.1080/00420988520080851.

Newman, P. and J. Kenworthy. 1989. Cities and Automobile Dependence. Aldershot: Gower Publications.

Newman, P. and J. R. Kenworthy. 1999. Sustainability and Cities. Overcoming Automobile Dependence. Washington, D.C. and Covelo, California: Island Press.

Nielsen, T. 2002. Boliglokalisering og transport $i$ Aalborg (Residential location and transport in Aalborg). Ph.D. thesis, Aalborg University, Aalborg.

Norusis, M. 1990. SPSS Base System User's Guide. Chicago.

Næss, P. 2004. Predictions, regressions and critical realism. Journal of Critical Realism, 2:133-164. doi: 10.1163/1572513041172713.

Næss, P. 2005. Residential location affects travel behavior-but how and why? the case of Copenhagen Metropolitan Area. Progress in Planning, 63(2):165 - 165. doi: 10.1016/j.progress.2004.08.002.

Næss, P. 2006a. Accessibility, activity participation and location of activities. exploring the links between residential location and travel behavior. Urban Studies, 43(3):627-652. doi: $10.1080 / 00420980500534677$.

Næss, P. 2006b. Urban structure matters. Residential location, car dependence and travel behaviour. London, New York: Routledge.

Næss, P. 2007. Residential location and travel in Hangzhou Metropolitan Area. NIBR Report 1, Norwegian Institute for Urban and Regional Research, Oslo.

Næss, P. 2008. Gender differences in the influences of urban structure on daily-life travel. In T. Priya and T. Cresswell, eds., Gendered Mobilities, pp. 173-192. Aldershot: Ashgate.

Næss, P. 2009. Residential self-selection and appropriate control variables in land use: Travel studies. Transport Reviews, 29(3):293 - 324. doi: 10.1080/01441640802710812.

Næss, P. and O. B. Jensen. 2004. Urban structure matters, even in a small town. Journal of Environmental Planning and Mangement, 47(1):35-57. doi: 10.1080/0964056042000189790.

Næss, P., P. G. Røe, and S. L. Larsen. 1995. Travelling distances, modal split and transportation energy in thirty residential areas in Oslo. Journal of Environmental Planning and Management, 38(3):349-370. doi: 10.1080/09640569512913.

Sayer, A. 1992. Method in Social Science: A Realist Approach. London: Routledge, 2 edition.

Schipper, L., E. Deakin, and D. Spearling. 1994. Sustainable transportation. the future of the automobile in an environmentally constrained world. In Paper presented at a seminar organized by Transportforskningsberedningen. Stockholm. 
Schwanen, T., F. M. Dieleman, and M. Dijst. 2001. Travel behaviour in Dutch monocentric and policentric urban systems. Journal of Transport Geography, 9(3):173 - 186. doi: 10.1016/S0966-6923(01)00009-6.

Smits, J. 2003. Estimating the Heckman two-stepprocedure to control for selection bias with SPSS. Nijmegen: Radboud University.

Stead, D. and S. Marshall. 2001. The relationships between urban form and travel patterns: An international review and evaluation. European Journal of Transport Infrastructure Research, $1(2): 113-141$.

Weinert, J., C. Ma, and X. Yang. 2006. The transition to electric bikes in China and its effect on travel behavior, transit use, and safety. In Paper for the Transportation Research Board's 86th Annual Meeting. URL http://hydrogen.its.ucdavis.edu/people/jxweinert/ ebikeschinamobility.

Williams, K., E. Burton, and M. Jenks. 2000. Achieving sustainable urban form: Conclusions. In K. Williams, E. Burton, and M. Jenks, eds., Achieving Sustainable Urban Form, pp. 347-355. London: Pion Limited.

Wu, Z. 2008. Introduction of transportation energy situation \& challenges in China. Presentation materials. URL http://www.acus.org/docs/WU_Transport.ppt.

Yang, J. 2006. Transportation implications of land development in a transitional economy. Transportation Research Record, 1954:7-14.

Zegras, C. 2010. The built environment and motor vehicle ownership \& use: Evidence from Santiago de Chile. Urban Studies, 47(8):1793-1817. doi: 10.1177/0042098009356125. 


\section{A The independent variables included in the multivariate analyses}

\begin{tabular}{lll}
\hline $\begin{array}{l}\text { Independent variable } \\
\text { Location of the }\end{array}$ & $\begin{array}{l}\text { Among outer-area residents, travel } \\
\text { distances longer in total, by car, and } \\
\text { by public transport; shorter by } \\
\begin{array}{l}\text { downtence relative to } \\
\text { (non-linear }\end{array}\end{array}$ & $\begin{array}{l}\text { Reasons for including the } \\
\text { variable in the analysis }\end{array}$ \\
$\begin{array}{l}\text { non-motorized modes. Higher } \\
\text { proportion traveled by car and lower } \\
\text { distance along the } \\
\text { road network) }\end{array}$ & $\begin{array}{l}\text { However, reduced effects at long } \\
\text { distances from downtown, and } \\
\text { possibly somewhat lower amount of } \\
\text { travel in the most peripheral areas. }\end{array}$ & $\begin{array}{l}\text { Urban structural variable of } \\
\text { investigation. Not a control } \\
\text { variable. }\end{array}$ \\
\hline $\begin{array}{l}\text { Logarithm of the } \\
\text { distance from the } \\
\text { residence to the closest } \\
\text { second-order urban } \\
\text { center }\end{array}$ & $\begin{array}{l}\text { Among those living far from a } \\
\text { second-order center, travel distances } \\
\text { longer in total, by car, and by public } \\
\text { transport; shorter by non-motorized } \\
\text { modes. Higher proportion of travel } \\
\text { by car; lower proportion of } \\
\text { pedestrian/bicycle travel. }\end{array}$ & $\begin{array}{l}\text { Urban structural variable of } \\
\text { primary interest in this } \\
\text { investigation. Not a control } \\
\text { variable. }\end{array}$ \\
\hline
\end{tabular}

\begin{tabular}{ll}
\hline & $\begin{array}{l}\text { Among those living far from a } \\
\text { third-order center, longer travel } \\
\text { distances in total and by car; shorter } \\
\text { Logarithm of the } \\
\text { distance from the } \\
\begin{array}{l}\text { residence to the closest } \\
\text { bird-order urban } \\
\text { center }\end{array}\end{array}$ \\
$\begin{array}{l}\text { proportion traveled by car. Possibly } \\
\text { more travel by non-motorized modes } \\
\text { (in order to reach the local service } \\
\text { facilities located nearby) }\end{array}$ \\
\hline
\end{tabular}

$\begin{array}{ll}\text { Sex }(\text { female }=1, \text { male } & \begin{array}{l}\text { Among women, shorter travel } \\ \text { distances in total and by car. Higher } \\ \text { proportion of travel by public } \\ \text { transport, and on foot or by bicycle. }\end{array}\end{array}$

Urban structural variable of primary interest in this investigation. Not a control variable.
The proportions of men and women among respondents varies somewhat between the areas. Also enables comparison of urban structural and demographic variables, and across population groups. 


\begin{tabular}{|c|c|c|}
\hline Independent variable & Assumed effects on travel behavior & $\begin{array}{l}\text { Reasons for including the } \\
\text { variable in the analysis }\end{array}$ \\
\hline Age & $\begin{array}{l}\text { Among the elderly, shorter travel } \\
\text { distances in total and by car, and } \\
\text { lower proportion of car travel. }\end{array}$ & $\begin{array}{l}\text { Age distribution varies } \\
\text { between the residential areas, } \\
\text { among others with a higher } \\
\text { proportion of young people in } \\
\text { the inner city. Also enables } \\
\text { comparison of urban } \\
\text { structural and demographic } \\
\text { variables. }\end{array}$ \\
\hline $\begin{array}{l}\text { Number of household } \\
\text { members below } 7 \\
\text { years of age }\end{array}$ & $\begin{array}{l}\text { If small children in household, } \\
\text { shorter travel distances in total and by } \\
\text { public transport, a higher proportion } \\
\text { of travel by car, and a lower } \\
\text { proportion by public transport. } \\
\text { Ambiguous expectations regarding } \\
\text { pedestrian and bicycle travel. }\end{array}$ & $\begin{array}{l}\text { Number of children varies } \\
\text { between the areas, among } \\
\text { others with fewer children in } \\
\text { the inner city and large local } \\
\text { variations in outer areas. Also } \\
\text { enables comparison of urban } \\
\text { structural and demographic } \\
\text { variables, and across } \\
\text { population groups. }\end{array}$ \\
\hline $\begin{array}{l}\text { Number of household } \\
\text { members aged } 7 \text { - } 17\end{array}$ & $\begin{array}{l}\text { If school-age children in household, } \\
\text { shorter travel distances by public } \\
\text { transport, a higher proportion of } \\
\text { travel by car, and a lower proportion } \\
\text { by public transport. Possibly a lower } \\
\text { proportion of travel on foot or by } \\
\text { bicycle. Ambiguous expectations } \\
\text { regarding the total travel distance. }\end{array}$ & $\begin{array}{l}\text { Number of children varies } \\
\text { between the areas, among } \\
\text { others with fewer children in } \\
\text { the inner city and large local } \\
\text { variations in outer areas. Also } \\
\text { enables comparison of urban } \\
\text { structural and demographic } \\
\text { variables, and across } \\
\text { population groups. }\end{array}$ \\
\hline $\begin{array}{l}\text { Workforce } \\
\text { participation (yes }=1 \text {, } \\
\text { no }=0)\end{array}$ & $\begin{array}{l}\text { Among workforce participants, } \\
\text { longer travel distances in total, by car, } \\
\text { and by public transport. Ambiguous } \\
\text { expectations regarding modal split } \\
\text { and the pedestrian/bicycle travel } \\
\text { distance. }\end{array}$ & $\begin{array}{l}\text { The proportion of workforce } \\
\text { participants varies between } \\
\text { the areas. Also enables } \\
\text { comparison of urban } \\
\text { structural and demographic } \\
\text { variables, and across } \\
\text { population groups. }\end{array}$ \\
\hline $\begin{array}{l}\text { Student/pupil (yes = } \\
1, \text { no }=0)\end{array}$ & $\begin{array}{l}\text { Shorter travel distances by car and } \\
\text { longer by public transport and } \\
\text { walk/bike among students/pupils, } \\
\text { with corresponding effects on the } \\
\text { modal split. Ambiguous expectations } \\
\text { regarding the total travel distance. }\end{array}$ & $\begin{array}{l}\text { The proportion of } \\
\text { students/pupils varies } \\
\text { between the areas, with } \\
\text { considerably higher shares in } \\
\text { the inner city. Also enables } \\
\text { comparison of urban } \\
\text { structural and demographic } \\
\text { variables, and across } \\
\text { population groups. }\end{array}$ \\
\hline
\end{tabular}




\begin{tabular}{|c|c|c|}
\hline Independent variable & Assumed effects on travel behavior & $\begin{array}{l}\text { Reasons for including the } \\
\text { variable in the analysis }\end{array}$ \\
\hline $\begin{array}{l}\text { Pensioner }(\text { yes }=1 \text {, no } \\
=0)\end{array}$ & $\begin{array}{l}\text { Somewhat shorter total travel } \\
\text { distance. Ambiguous expectations } \\
\text { regarding modal split and the } \\
\text { distances traveled by the various } \\
\text { modes. }\end{array}$ & $\begin{array}{l}\text { The proportion of pensioners } \\
\text { varies between the areas. Also } \\
\text { enables comparison of urban } \\
\text { structural and demographic } \\
\text { variables, and across } \\
\text { population groups. }\end{array}$ \\
\hline $\begin{array}{l}\text { Personal annual } \\
\text { income ( } 1000 \text { yuan })\end{array}$ & $\begin{array}{l}\text { Among high earners, longer travel } \\
\text { distances in total and by car, and a } \\
\text { higher proportion traveled by car. } \\
\text { Lower proportions of travel by public } \\
\text { transport and non-motorized modes. }\end{array}$ & $\begin{array}{l}\text { Income levels vary } \\
\text { considerably between the } \\
\text { areas. Also enables } \\
\text { comparison of urban } \\
\text { structural and demographic } \\
\text { variables, and across } \\
\text { population groups. }\end{array}$ \\
\hline $\begin{array}{l}\text { Whether the } \\
\text { respondent holds a } \\
\text { driver's license for car } \\
\text { (yes }=1, \text { no }=0 \text { ) }\end{array}$ & $\begin{array}{l}\text { Longer travel distances in total and by } \\
\text { car, and a higher proportion traveled } \\
\text { by car among those who wold a } \\
\text { driver' license. Shorter distance } \\
\text { traveled by public transport and a } \\
\text { lower proportion of this mode. } \\
\text { Maybe somewhat more walk/bike } \\
\text { travel, as these modes, alike with the } \\
\text { car, are individual and provide some } \\
\text { of the same flexibility. }\end{array}$ & $\begin{array}{l}\text { The proportion holding a } \\
\text { driver's license varies between } \\
\text { the areas. Arguably, though, } \\
\text { the part of this variation not } \\
\text { due to factors already } \\
\text { included as variables in the } \\
\text { analysis may be, to a large } \\
\text { extent, a result of urban } \\
\text { structural conditions, and } \\
\text { should therefore perhaps not } \\
\text { be controlled for. }\end{array}$ \\
\hline
\end{tabular}

$\begin{array}{ll} & \begin{array}{l}\text { Longer travel distances in total and by } \\ \text { car, and a higher proportion traveled }\end{array} \\ \text { Availability of a } & \text { by car if one or more cars is available } \\ \text { private car in the } & \text { in the household. Shorter distance } \\ \text { household } & \text { traveled by public transport and } \\ & \text { walk/bike, and lower proportions of } \\ & \text { these modes. }\end{array}$

Car ownership varies between the areas. Arguably though, the part of this variation which is not due to factors already included as variables in the analysis may to some extent be a result of urban structural conditions, and should therefore perhaps not be controlled for. 


\begin{tabular}{lll}
\hline $\begin{array}{l}\text { Independent variable } \\
\text { Education level } \\
\text { (professional } \\
\text { secondary school or } \\
\text { higher levels }=1, \\
\text { otherwise 0) }\end{array}$ & $\begin{array}{l}\text { Among those with significant } \\
\text { technical or economic education, } \\
\text { longer travel distances in total, by car } \\
\text { and by public transport. Possibly a } \\
\text { lower proportion of travel on foot or } \\
\text { by bicycle. }\end{array}$ & $\begin{array}{l}\text { Reasons for including the } \\
\text { variable in the analysis }\end{array}$ \\
\hline $\begin{array}{l}\text { of education varies between } \\
\text { the areas. Also enables } \\
\text { comparison of urban } \\
\text { structural and demographic } \\
\text { variables, and across } \\
\text { population groups. }\end{array}$ \\
$\begin{array}{l}\text { Index for attitudes to } \\
\text { transport issues (high } \\
\text { value = car-oriented } \\
\text { attitudes) }\end{array}$ & $\begin{array}{l}\text { Among those with car-oriented } \\
\text { attitudes, longer travel distances in } \\
\text { total and by car; shorter by public } \\
\text { transport and walking/bicycling. A } \\
\text { higher proportion of car travel and } \\
\text { lower proportions of public transport } \\
\text { and non-motorized modes. }\end{array}$ & $\begin{array}{l}\text { Transport attitudes vary } \\
\text { between the areas, and this } \\
\text { may imply self-selection of } \\
\text { residents into neighborhoods } \\
\text { matching their travel } \\
\text { preferences. Arguably though, } \\
\text { the part of this variation not } \\
\text { due to factors already } \\
\text { included as variables in the } \\
\text { analysis may to a high extent } \\
\text { be a result of urban structural } \\
\text { conditions, and should } \\
\text { therefore perhaps not be } \\
\text { controlled for. }\end{array}$ \\
& &
\end{tabular}

Index for attitudes to
environmental issues
(high value $=$
environmentally
oriented attitudes)

Shorter travel distances in total and by car, and longer by non-motorized modes among those with environmentally oriented attitudes.

Same as for the previous Also a lower proportion of car travel and a higher proportion of walk/bike.

Residential
preferences
(mentioning
proximity to public
transport, workplace
and/or shopping
opportunities
important residential
choice criteria $=1$,
otherwise 0 )

Among those reporting proximity to daily destinations and public transport stops as important residential choice criteria, shorter travel distances and less car driving. variable.

$$
\begin{aligned}
& \text { Residential preferences may } \\
& \text { vary between the areas, and } \\
& \text { this may imply self-selection } \\
& \text { of residents into } \\
& \text { neighborhoods matching } \\
& \text { their travel preferences. }
\end{aligned}
$$




\begin{tabular}{|c|c|c|}
\hline Independent variable & Assumed effects on travel behavior & $\begin{array}{l}\text { Reasons for including the } \\
\text { variable in the analysis }\end{array}$ \\
\hline $\begin{array}{l}\text { Regular transport of } \\
\text { children to school or } \\
\text { kindergarten (yes }=1 \text {, } \\
\text { no }=0 \text { ) }\end{array}$ & $\begin{array}{l}\text { Among those who transport children } \\
\text { regularly, longer travel distance by car, } \\
\text { a higher proportion of travel by car } \\
\text { and a lower proportion by public } \\
\text { transport. Maybe also somewhat } \\
\text { longer total travel distance. } \\
\text { Ambiguous expectations regarding } \\
\text { the distance by walk/bike and the } \\
\text { proportion of such travel. }\end{array}$ & $\begin{array}{l}\text { The proportions with such } \\
\text { responsibilities vary between } \\
\text { the areas, maybe in a way } \\
\text { different from the variation in } \\
\text { the number of children in the } \\
\text { households. }\end{array}$ \\
\hline $\begin{array}{l}\text { Overnight stays away } \\
\text { from home more than } \\
\text { three nights during } \\
\text { the investigated week } \\
(\text { yes }=1, \text { no }=0)\end{array}$ & $\begin{array}{l}\text { Longer travel distances in total, by car } \\
\text { and by public transport, and a lower } \\
\text { proportion of walk/bike among those } \\
\text { who have many overnight stays away } \\
\text { from home }\end{array}$ & $\begin{array}{l}\text { A sort of "noise" which it } \\
\text { might be desirable to } \\
\text { eliminate in the estimation of } \\
\text { the effects of the other } \\
\text { variables. }\end{array}$ \\
\hline $\begin{array}{l}\text { Official trips during } \\
\text { the investigated week } \\
\text { (yes }=1, \text { no }=0 \text { ) }\end{array}$ & $\begin{array}{l}\text { Among those who have taken official } \\
\text { trips, longer travel distances in total, } \\
\text { by car, and by public transport; lower } \\
\text { proportion of travel on foot or by } \\
\text { bicycle. }\end{array}$ & $\begin{array}{l}\text { A sort of "noise" which it } \\
\text { might be desirable to } \\
\text { eliminate in the estimation of } \\
\text { the effects of the other } \\
\text { variables. }\end{array}$ \\
\hline $\begin{array}{l}\text { Has moved to the } \\
\text { present dwelling less } \\
\text { than five years ago (yes } \\
=1, \text { no }=0 \text { ) }\end{array}$ & $\begin{array}{l}\text { Among those who moved recently, } \\
\text { longer total travel distance for all } \\
\text { modes (in particular during } \\
\text { weekends). More travel by car and } \\
\text { public transport, and less by } \\
\text { non-motorized modes. }\end{array}$ & $\begin{array}{l}\text { The proportion of people who } \\
\text { have moved is likely to vary } \\
\text { between the areas (some areas } \\
\text { are characterized by higher } \\
\text { turnover than other areas). }\end{array}$ \\
\hline
\end{tabular}

